\title{
The Effect of QPF on Real-Time Deterministic Hydrologic Forecast Uncertainty
}

\author{
THOMAS E. ADAMS III ${ }^{\mathrm{a}}$ AND RANDEL DYMOND \\ Department of Civil and Environmental Engineering, Virginia Polytechnic Institute and State University \\ Blacksburg, Virginia
}

(Manuscript received 15 September 2018, in final form 19 June 2019)

\begin{abstract}
The use of quantitative precipitation forecast (QPF) in hydrologic forecasting is commonplace, but QPF is subject to considerable error. When QPF is included as a model forcing in the hydrological forecast process, significant error propagates through the hydrologic predictions. Two questions arise: 1) are the resulting observed hydrologic forecast errors sufficiently large to suggest the use of zero QPF in the forecast process, and 2) if the use of nonzero QPF is indicated, how many periods (hours) of QPF $(1,6,12, \ldots, 72 \mathrm{~h})$ should be used? Also, do forecast conditions exist under which the use of QPF should be different? This study presents results from two real-time hydrologic forecast experiments, focused on the NOAA/NWS Ohio River Forecast Center (OHRFC). The experiments rely on forecasts from subbasins at 39 forecast point locations, ranging in drainage area, geographic location within the Ohio River Valley, and watershed response time. Results from an experiment, spanning all flow ranges, for the 10 August 2007-31 August 2009 period, show that nonzero QPF produces smaller hydrologic forecast error than zero QPF. A second experiment, 23 January 2009-15 September 2010, suggests that QPF should be limited to 6-12-h duration for flood forecasts. Beyond $12 \mathrm{~h}$, hydrologic forecast error increases substantially across all forecast ranges, but errors are much larger for flood forecasts. Increased durations of QPF produce smaller forecast error than shorter QPF durations only for nonflood forecasts. Experimental results are shown to be consistent with NWS April 2001-October 2016 forecast verification statistics for the OHRFC.
\end{abstract}

\section{Introduction}

Single-valued, deterministic quantitative precipitation forecast (QPF) is a commonly used model forcing in hydrologic forecasting (Georgakakos and Hudlow 1984; Sokol 2003; Adams and Pagano 2016; Li et al. 2017). All 13 U.S. National Oceanic and Atmospheric Administration (NOAA)/National Weather Service (NWS) River Forecast Centers (RFCs) utilize QPF operationally for hydrologic forecasting, ranging in duration from 1 to 10 days (Adams 2016). Despite its widespread operational use, verification studies show there are considerable spatial and temporal errors associated with QPF. For instance, Charba et al. (2003) show that for both 6- and 24-h forecast periods, QPF errors are on the order of $\geq 50 \%$ for Weather Prediction Center (WPC), RFC, and numerical weather

\footnotetext{
${ }^{a}$ Current affiliation: TerraPredictions, Blacksburg, Virginia.
}

Corresponding author: Thomas E. Adams III, tea@ terrapredictions.org prediction (NWP) model values, for all precipitation intervals, including higher categories, $25.4-50.8 \mathrm{~mm}$ (1.0-2.0 in.) and $\geq 50.8 \mathrm{~mm}$ (2.0 in.), which are more likely to be associated with flooding. Additionally, NOAA/NWS (2019a) shows, from long-term QPF verification analyses, that threat score decreases and bias increases with longer (1-3 days) QPF lead times.

Research has demonstrated that the use of deterministic QPF introduces considerable error into hydrologic forecasting (Cuo et al. 2011; Diomede et al. 2014). Welles et al. (2007) state that with hydrologic forecasts "models are driven into the future with forecast precipitation and temperature, and therefore much of the uncertainty in the forecasts is exogenous to the hydrologic modeling process. One important task for anyone conducting hydrologic verification in the future will be to analyze how the internal and external sources of error interact and limit the predictability of the hydrologic systems." Sources of hydrologic forecast uncertainty, including QPF, are recognized by the National Research Council (2006). Adams and Dymond (2018, manuscript submitted to 
J. Hydrol.) report on the magnitude of QPF uncertainty over the conterminous United States (CONUS). They illustrate, using data from the NOAA/NWS National Precipitation Verification Unit (NPVU; Charba et al. 2003), that for the period June 2001-December 2009, both RMSE and MAE values for the highest QPF precipitation category, $\geq 1.0 \mathrm{in}$. $(25.4 \mathrm{~mm})$, for RFC, WPC, and NWP models, averaged $\sim 1.0 \mathrm{in}$. $(25.4 \mathrm{~mm})$, implying errors approximately $\pm 100 \%$. Median correlations of QPF versus observed precipitation ranged between $\sim 0.0$ and $\sim 0.1$ for 24 -h QPF over the study period, for the same QPF sources. Further analyses, utilizing a Monte Carlo hydrologic modeling experiment, by Adams and Dymond (2018, manuscript submitted to J. Hydrol.), show that large peak flow prediction uncertainties are obtained from the use of deterministic QPF for a representative $3533-\mathrm{km}^{2}$ watershed in the Ohio River Valley. For the purposes of hydrologic forecasting, which requires accurate placement of precipitation inputs, these QPF errors are very significant.

Recent hydrometeorological verification research has focused on object-based metrics such as Lack et al. (2010), whose interest centered on improving methods to account for error measures from differences in matched objects due to displacement, dilation, rotation, and intensity, and Rempel et al. (2017), who investigated verification of convective development using geostationary satellite data. Lack et al. (2010) recognize that "quantitative precipitation forecasts (QPFs) ... remain the toughest obstacle to short-term forecasting, and are essential to the accurate prediction of severe weather threats." Clearly, however, these recently developed object-based methods are aimed at strictly meteorological applications, as Rempel et al. (2017) state that traditional scores "are insufficient for the evaluation of cloud and precipitation processes in high-resolution NWP forecasts since they do not take into account information about the spatial structure and irregular morphology of these fields." While we understand the importance of capturing spatial field patterns to NWP modelers, the principal concern in hydrologic forecasting is accurate quantification of the hydrologic model forcings over the watersheds of interest. Consequently, accurate spatial placement is paramount.

Despite the advances in our understanding of QPF errors, unanswered questions remain with the use of deterministic QPF in hydrologic forecasting. Namely, we can ask the following:

- Due to the large magnitude of QPF errors and subsequent hydrologic forecast errors that result from its use, should nonzero deterministic QPF be used in hydrologic forecasting?
- If the use of nonzero QPF is warranted, are there limits to its use such as, for example, how many QPF forecast periods are warranted before hydrologic prediction errors become unacceptably large?

\section{a. Background}

NWS RFCs are responsible for providing routine river and flood forecasts of stage/flow values to the general public and others on a daily basis, often including evening updates. Additional forecasts are issued during operational periods, as needed, during flooding episodes, subject to changing meteorological conditions, including $24 \mathrm{~h}$ per day operational coverage. Routine operations at NWS River Forecast Centers utilize a 6-h time step for model forcings, internally, and output. That is, observed hourly rain gauge and radar-derived precipitation is aggregated to 6-hourly, subbasin averaged amounts. QPF guidance products obtained from the NWS WPC, formerly Hydrometeorological Prediction Center, and produced at RFCs for operational use, are 6-hourly, subbasin averaged values.

\section{1) Hydrologic Modeling}

RFCs currently use the NWS Community Hydrologic Prediction System (CHPS)-based on the Flood Early Warning System (FEWS; Deltares 2018) as the basis of their modeling system (Adams 2016). All RFC CHPS modeling is predominantly interactive, as described by Adams and Smith (1993) and Adams (2016), within the Linux-based NOAA/NWS Advanced Weather Interactive Processing System (AWIPS; NRC 1997, 2006). CHPS implementation began at the NOAA/NWS Ohio River Forecast Center (OHRFC) early in 2010 with full operational use of CHPS starting in February 2012. The OHRFC uses the Sacramento Soil Moisture Accounting (SAC-SMA) model (Burnash et al. 1973; Burnash 1995), SNOW-17 snow accumulation and ablation model (Anderson 1973), several lumpedparameter hydrologic routing models, and three reservoir simulation models within the CHPS operational environment. CHPS models were migrated from the legacy NWS River Forecast System (NWSRFS; NOAA/NWS 1972).

\section{2) Model FORCINGS}

In addition to QPF, principal hydrologic model forcings are observed precipitation and observed and forecasted temperature. Precipitation observations are obtained from a multisensor estimation process, involving rain gauges, NWS Next Generation Weather Radar (NEXRAD) Doppler radar, and, in some instances, remotely sensed 


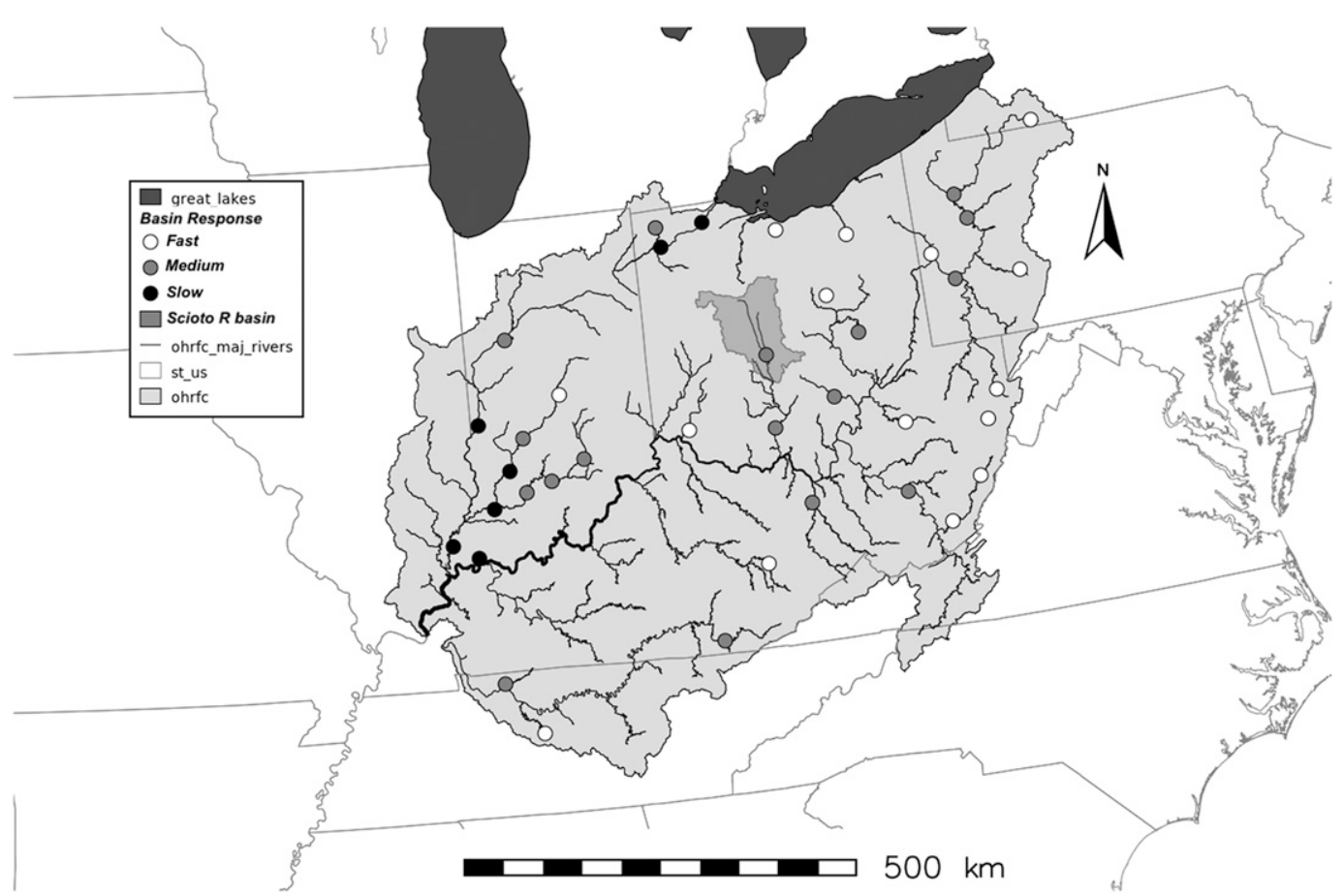

FIG. 1. Map showing the location of 39 experiment 1 and experiment 2 forecast point locations used in the OHRFC forecast area (gray shading), listed in Tables 1 and 2, identifying fast, medium, and slow responding basins. The Scioto River basin defined at Circleville, OH (USGS ID 03230700), is shown with dark gray shading.

satellite estimates of precipitation (Kitzmiller et al. 2013). Forecasted precipitation is derived from NWP models, usually with meteorological forecaster adjustments made at both the WPC, and/or at local RFCs (Novak et al. 2014). The hydrologic forecast process in other countries is similar to that used in the United States (Adams and Pagano 2016).

\section{b. Research goals}

The aim of this research is to frame the potential limits to the use of deterministic QPF for hydrologic forecasting in an operational setting. Section 2 of this paper describes two real-time hydrologic forecasting experiments used in this study. We focus model simulations on watersheds in the OHRFC area of responsibility, shown in Fig. 1. The first experiment addresses the issue of whether or not nonzero deterministic QPF should be used in hydrological forecasting. The second experiment identifies the expected range of hydrologic forecast error using QPF for OHRFC forecast point locations and a possible limit to the duration of QPF that should be used for flood forecasting before forecast error grows too large for acceptable use. Results of the experiments are presented in section 3. The overall context of the experimental results in relation to other RFCs and the conditions under which the use of QPF should possibly be limited are identified in section 4. Section 5 summarizes the experimental results and presents conclusions.

\section{Research approach}

Two sets of real-time hydrologic forecast experiments are presented. The experiments, which were made using the legacy NWSRFS, rely on a geographically broad distribution of forecast point locations, with varying basin sizes and hydrologic response times for the OHRFC. Basins are categorized as fast, medium, and slow responding at 39 forecast point locations, shown in Fig. 1 and listed in Tables 1 and 2. These include 15 fast, 17 medium, and 7 slow responding forecast point locations. The terms slow, medium, and fast refer to typical hydrograph time-to-peak response times. Response times less than $24 \mathrm{~h}$ are classified as fast, response times between 24 and $60 \mathrm{~h}$ are considered medium, and response times greater than $60 \mathrm{~h}$ are considered slow (see NOAA/NWS 2001).

NWSRFS was used as the underlying modeling framework for the experimental studies because CHPS was not available at the time the experiments were run. Calibrations of SAC-SMA, SNOW-17, channel routing, and reservoir simulation models for operational use for 
TABLE 1. Experiment 1 and 2 basins, listing NWS station identifier (ID), USGS identifier, station name, response time category, and basin area.

\begin{tabular}{lclcc}
\hline \multicolumn{1}{c}{ ID } & USGS ID & \multicolumn{1}{c}{ Name } & Area $\left(\mathrm{km}^{2}\right)$ & Response \\
\hline ALDW2 & 03183500 & Alderson, WV & 3533 & Fast \\
BEAP1 & 03107500 & Beaver Falls, PA & 8044 & Fast \\
BUCW2 & 03182500 & Buckeye, WV & 1399 & Fast \\
DLYW2 & 03050000 & Daily, WV & 479 & Fast \\
FRAT1 & 03432350 & Franklin, TN & 497 & Fast \\
GRTW2 & 03153500 & Grantsville, WV & 2365 & Fast \\
INDI3 & 03353000 & Indianapolis, IN & 4235 & Fast \\
JKNK2 & 03280000 & Jackson, KY & 2852 & Fast \\
KILO1 & 03139000 & Kilbuck, OH & 1202 & Fast \\
MILO1 & 04199000 & Milan, OH & 961 & Fast \\
MLGO1 & 03245500 & Milford, OH & 3116 & Fast \\
OLNN6 & 03010820 & Olean, NY & 3087 & Fast \\
OLPO1 & 04206000 & Old Portage, OH & 1046 & Fast \\
PSNW2 & 03069500 & Parsons, WV & 1870 & Fast \\
SWDP1 & 03041500 & Seward, PA & 1852 & Fast \\
\hline
\end{tabular}

all OHRFC subbasins were completed prior to the time the experiments started, following guidelines presented by Anderson (2002) and Smith et al. (2013), principally using manual methods. Model experiments were conducted using 1200 UTC model initializations following routine OHRFC operations, which includes a manual data assimilation period ( -5 days through the 1200 UTC initialization) utilizing observed precipitation and temperature model forcings as described in Adams (2016). Experiments 1 and 2 both utilize QPF starting from 1200 UTC. The model initialization at 1200 UTC is identical for each QPF scenario to guarantee invariant initial conditions and basin memory for each subbasin and QPF scenario. Operational and experimental simulations utilize a 6-h time step for model forcings, internally, and output. The two experiments are focused on answering the respective questions

1) Should nonzero QPF be used in hydrologic forecasting?

2) If the use of nonzero QPF is suggested, what duration of QPF seems warranted?

Forecasts are evaluated on the basis of comparisons between U.S. Geological Survey (USGS) stage observations and simulated river stage values. Results from the experiment are reported in terms of forecast accuracy measures suggested for continuous hydrologic variables as suggested by Welles (2005), Welles et al. (2007), and Demargne et al. (2009), using mean error (ME), mean absolute error (MAE), and root-meansquare error (RMSE). The OHRFC hydrologic forecast lead times in this study are 7 days $(168 \mathrm{~h})$; QPF generally consists of four 6-h periods per day, which may include zero or nonzero values or both, as forecasted by WPC.
TABLE 2. Experiment 1 and 2 basins, listing NWS station identifier (ID), USGS identifier, station name, response time category, and basin area.

\begin{tabular}{lrlrl}
\hline \hline & & & \\
\multicolumn{1}{c}{ ID } & USGS ID & \multicolumn{1}{c}{ Name } & $\begin{array}{r}\text { Area } \\
\left(\mathrm{km}^{2}\right)\end{array}$ & Response \\
\hline ATHO1 & 03159500 & Athens, OH & 2442 & Medium \\
BEDI3 & 03371500 & Bedford, IN & 10000 & Medium \\
CDIO1 & 03142000 & Cambridge, OH & 1052 & Medium \\
CKVT1 & 03436500 & Clarksville, TN & 41173 & Medium \\
COLO1 & 03227500 & Columbus, OH & 4219 & Medium \\
FLRK2 & 03215000 & Fullers Station, KY & 10093 & Medium \\
FRKP1 & 03025500 & Franklin, PA & 15493 & Medium \\
KANW2 & 03193000 & Kanawha Falls, WV & 21681 & Medium \\
LAFI3 & 03335500 & West Lafayette, IN & 18121 & Medium \\
PARP1 & 03031500 & Parker, PA & 19868 & Medium \\
PKTO1 & 03237020 & Piketon, OH & 15115 & Medium \\
PTTP1 & 03085152 & Pittsburgh, PA & 49471 & Medium \\
SERI3 & 03365500 & Seymour, IN & 6063 & Medium \\
SHLI3 & 03373500 & Shoals, IN & 12761 & Medium \\
SPNI3 & 03357000 & Spencer, IN & 7739 & Medium \\
STRO1 & 04185000 & Stryker, OH & 1062 & Medium \\
WLBK2 & 03404000 & Williamsburg, KY & 4162 & Medium \\
DEFO1 & 04192500 & Defiance, OH & 14361 & Slow \\
EVVI3 & 03322000 & Evansville, IN & 277600 & Slow \\
HUFI3 & 03341500 & Terre Haute, IN & 31766 & Slow \\
NHRI3 & 03378500 & New Harmony, IN & 75716 & Slow \\
NWBI3 & 03360500 & Newberry, IN & 12142 & Slow \\
PTRI3 & 03373980 & Petersburg, IN & 28808 & Slow \\
WTVO1 & 04193500 & Waterville, OH & 16395 & Slow \\
\hline & & & & \\
\hline
\end{tabular}

All QPF values beyond the duration of QPF, such as 6-, 12-, 24-, 36-, 48-, and 72-h durations (at 6-h intervals), out to the 168-h hydrologic forecast lead time, are zero valued. For example, a 6-h duration QPF would consist of 1 period of WPC QPF, followed by 27 periods of zero-valued QPF. A 24-h QPF is composed of 4 periods of WPC QPF, followed by 24 periods of zero-valued QPF.

\section{a. Experiment 1}

Watersheds are identified to obtain a range of drainage basin areas and locations. The experiment was designed to investigate the use of WPC QPF based on daily, with 1200 UTC initializations, hydrologic forecasts for each of the 39 basins, shown in Fig. 1.

The operational and experimental forecasts were made for the period 10 August 2007-31 August 2009, using 24-h duration (four 6-h periods per day) QPF. The experimental period spanned 753 days at 39 locations, with 28 forecast periods each (four 6-h periods per day for 7 days), resulting in 801192 forecast verification pairs for analysis. The overall experimental design was structured to assess if nonzero QPF produces smaller error in hydrologic forecasts than zero QPF. Results from two experimental forecast scenarios are analyzed: no QPF (i.e., zero-valued QPF) and with WPC QPF. 

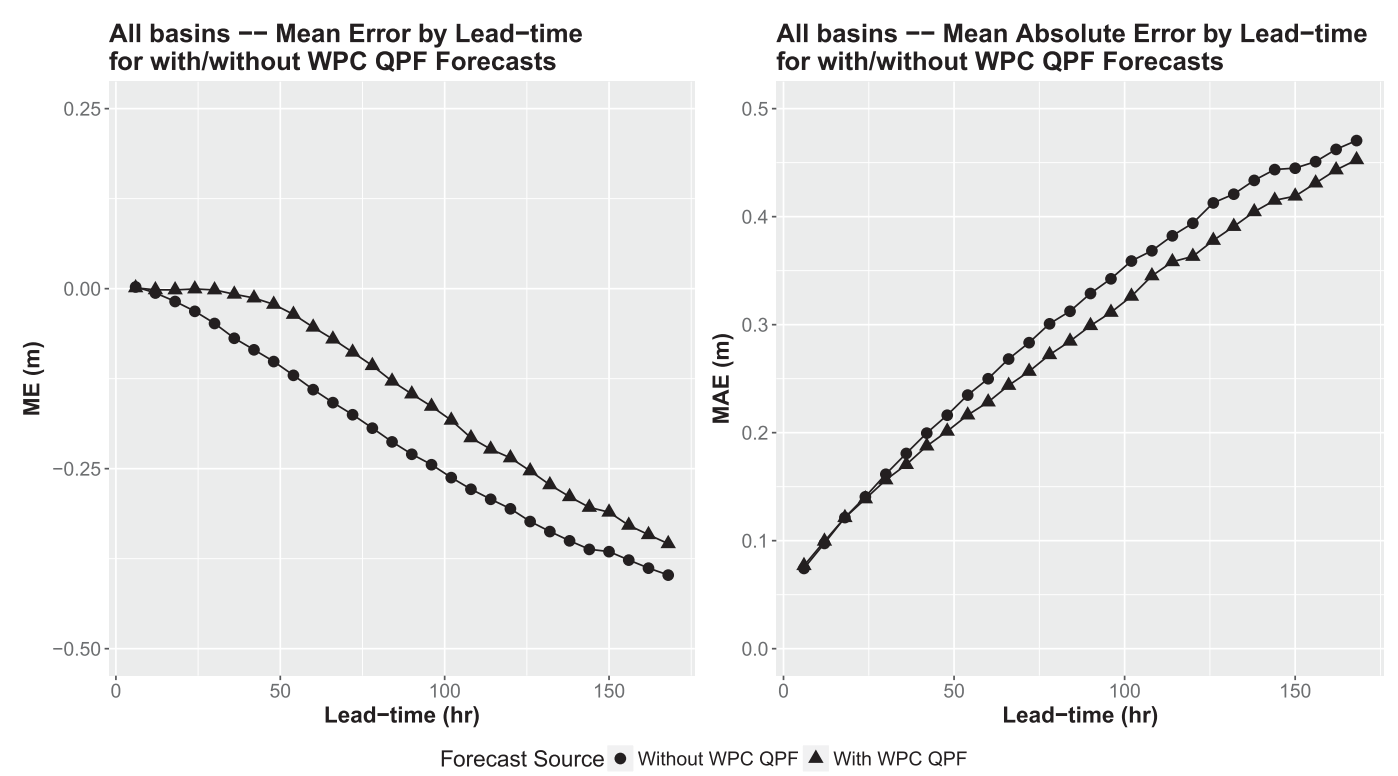

FIG. 2. Experiment 1, showing a comparison of OHRFC hydrologic forecasts both with and without WPC QPF, showing (left) ME and (right) MAE for all basins and response times, for the OHRFC operational forecast area. Shown for the period 10 Aug 2007-31 Aug 2009.

\section{b. Experiment 2}

QPF from the NOAA/NWS WPC, for 6-, 12-, 24-, 36-, 48-, and 72-h durations (at 6-h intervals), was used to generate real-time experimental hydrologic forecasts on a daily basis, in parallel with operational forecasts at the OHRFC, for the period 23 January 2009 through 15 September 2010. WPC QPF was used in the experiment because WPC QPF was available at 72-h lead times, where OHRFC QPF, at the time of the experiments, was only routinely available for 24 -h durations. The experimental period spanned 601 days at 39 locations, with 28 forecast periods each (four 6-h periods per day for 7 days), resulting in 639464 forecast verification pairs for analysis. No differences exist in models used or procedures between the experimental and operational hydrologic forecasts except that, for the experimental forecasts,

- the source of the QPF is the WPC, rather than the OHRFC Hydrometeorological Analysis and Support unit QPF, and

- the length of the QPF varies, at 6-, 12-, 24-, 36-, 48-, and 72-h durations (at 6-h intervals), rather than a single fixed 24-h duration (four 6-h periods per day).

In the experimental analyses we examine both hydrologic forecast accuracy, with respect to forecasted stream and river stage, and the detection of floods with probability of detection (POD) and false alarm ratio (FAR).

\section{Experimental results}

\section{a. Experiment 1}

Statistical forecast verification results from the simulated forecasts for Experiment 1 are presented graphically in Figs. 2 and 3 for the with and without WPC QPF forecast scenarios, by lead times ranging from 6 to $168 \mathrm{~h}$, at 6-h intervals. The verification measures shown are ME, MAE, and RMSE. Some immediate findings are as follows:

1) Results shown in Fig. 2 (right) for MAE and Fig. 3 (top left) for RMSE indicate that in the first 1-4 forecast periods, little difference is found between forecasts with and without WPC QPF when forecasts are aggregated across all locations.

2) Figure 2 (left), for ME values, indicates that differences between forecasts with and without WPC QPF are evident beginning in the second forecast lead time period $(12 \mathrm{~h})$.

3) As Fig. 3 illustrates with stratification between fast, medium, and slow responding basins, RMSE values differ little between lead times of 6 and $24 \mathrm{~h}$ (periods 1-4) for medium-response basins and with all basins lumped together, and through period 8 for slowresponding basins.

4) For fast responding basins, RMSE values are lower for the without WPC QPF forecasts for lead times 6-18h (periods 1-3) than the with WPC QPF forecasts, which suggests greater sensitivity by fast responding basins to QPF errors compared to medium and slow response basins. 

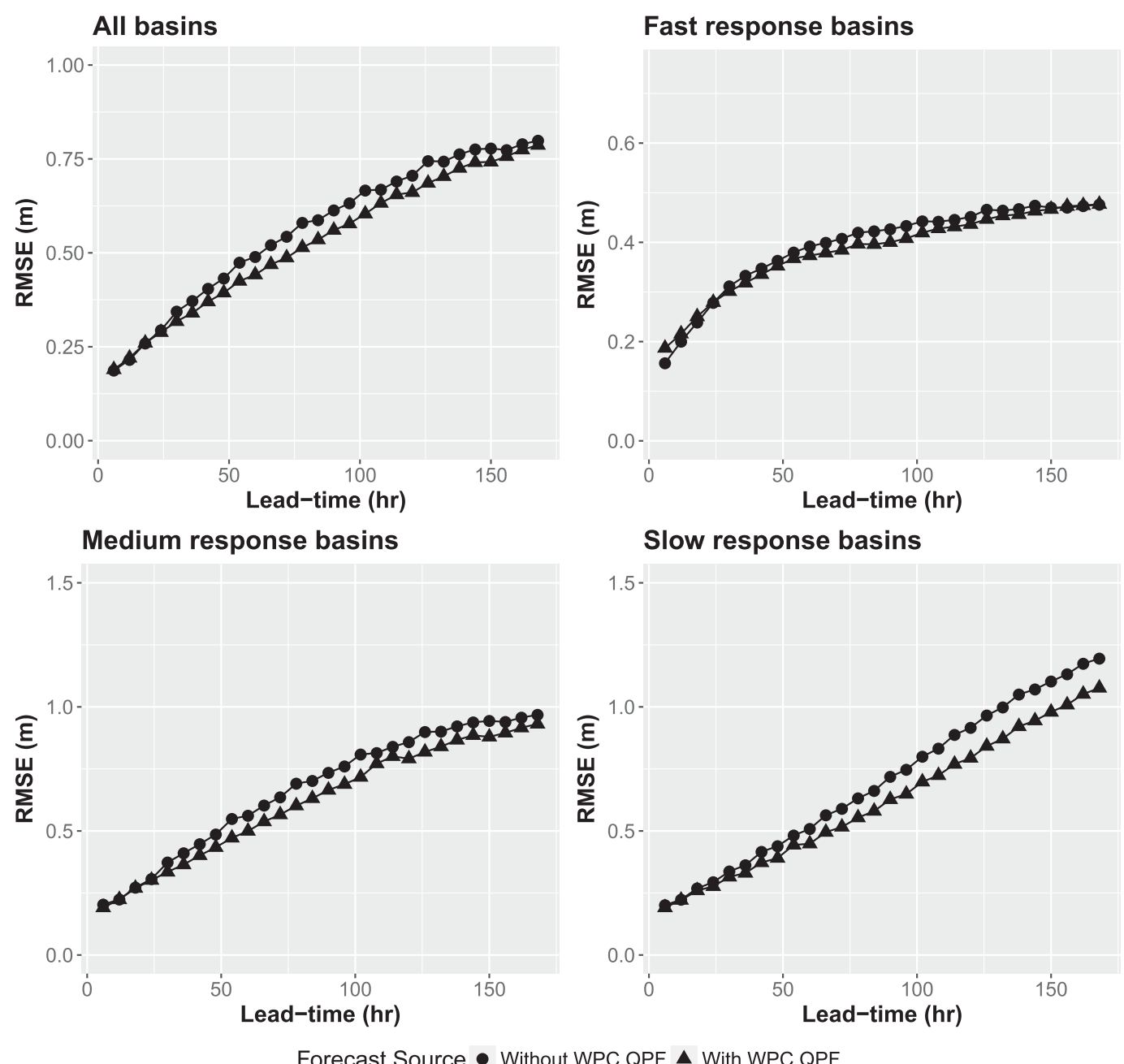

FIG. 3. Experiment 1, with 24-h WPC QPF, showing RMSE of OHRFC hydrologic forecasts for both with and without WPC QPF, for (top left) all basins and (top right) fast, (bottom left) medium, and (bottom right) slow response basins for the OHRFC operational forecast area. Shown for the period 10 Aug 200731 Aug 2009.

In general, the benefit gained from the use of nonzero QPF versus zero QPF in OHRFC hydrologic forecasts is shown by lower magnitudes of ME, MAE, and RMSE values with nonzero QPF compared to zero QPF. That is, experiment 1 shows that nonzero QPF in hydrologic forecasting produces lower error with longer lead times than for zero-QPF forecasts. It should be noted that these results cover the full range of flows, including both below and above flood stage forecasts.

Full 24-h duration (four 6-h periods per day) WPC QPF was used for the experimental QPF scenarios, which was, at the time, the duration of QPF used operationally at the OHRFC. Experiment 2 investigates the influence of the duration of QPF on hydrologic forecast error.

\section{b. Experiment 2}

All verification analyses in experiment 2 evaluated with respect to above/below flood levels are made on the basis of the forecasts, not the observations. This is done because flood alerts and warnings, derived from the hydrologic forecasts, are initially issued by the NWS on the basis of the forecasts and have greater bearing on the public in terms of disaster response and defense. Experiment 2 results are summarized in Figs. 4-10. Table 3 provides detailed results of ME, MAE, and RMSE verification measures for fast response basins. The following observations can be made:

1) With all basin locations grouped together, verification results in the top panels of Fig. 4 show that the magnitude of MAE and ME values increase with longer durations of QPF. Slight difference between 

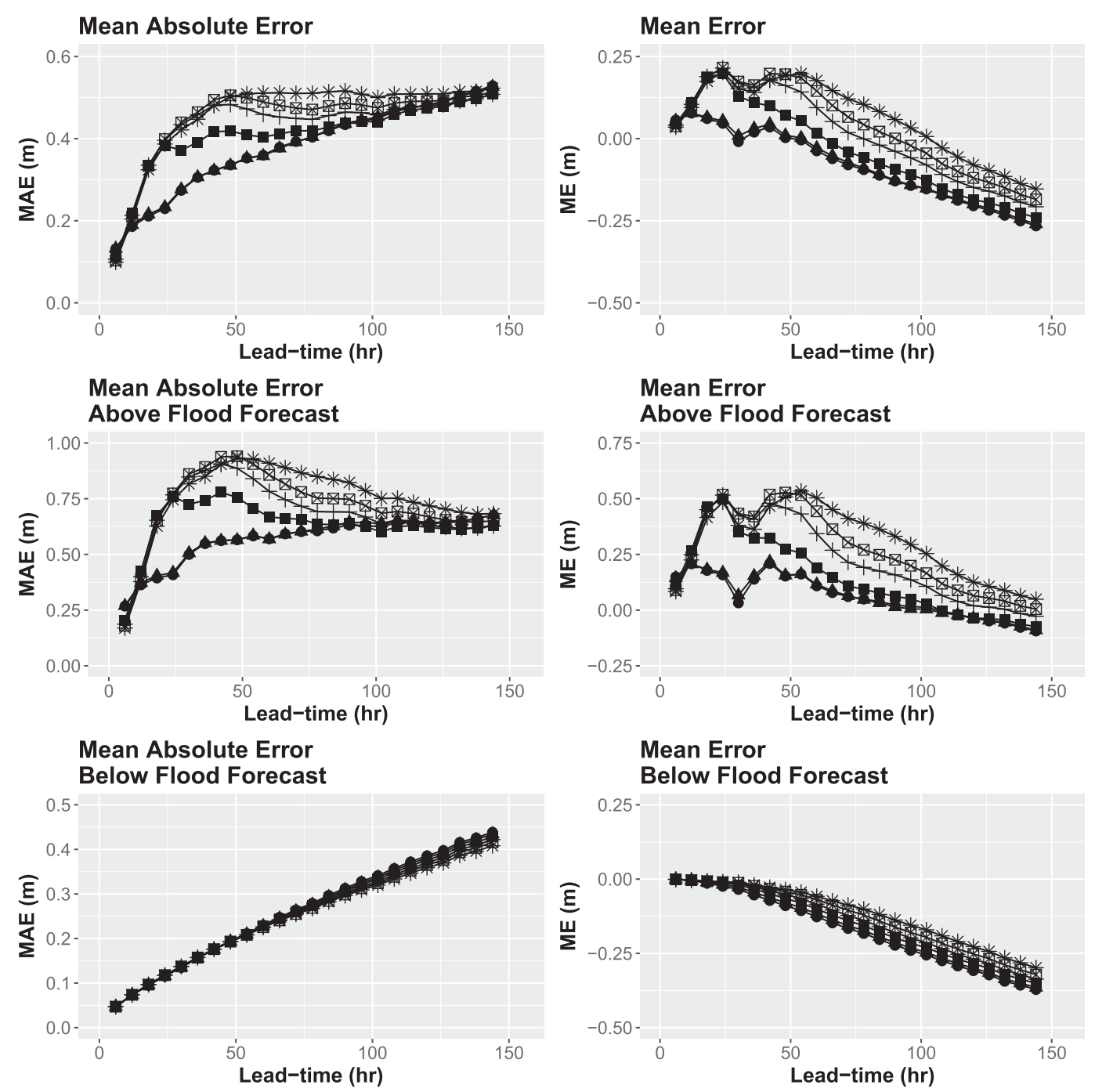

QPF Duration $\bullet 6 \quad \square 24 \otimes 48$

(hours) $\quad \Delta 12+36 * 72$

FIG. 4. Experiment 2 (left) MAE and (right) ME for (top) all basins and for both (middle) above and (bottom) below flood stage category forecasts, by lead time for all 39 basins, with QPF ranging from 6- to 72-h durations. Shown for the period 23 Jan 2009-15 Sep 2010.

ME and MAE lines for all basins aggregated (Fig. 4, top panel) and above flood forecasts (Fig. 4, middle panel) are due to small differences in samples between QPF durations because of differences in flood detection.

2) When basins are stratified according to above and below flood level forecasts categories, nonflood (below flood) level forecasts exhibit reduced forecast error with longer durations of QPF compared to above flood forecasts. In other words, flood forecasts show larger errors than nonflood forecasts with increased QPF durations, which is reflected in results from operational RFC forecasts shown in Tables 4 and 5 for the period April 2001-October 2016.
3) Little or no change in hydrologic forecast error is observed with increasing the duration of QPF from 6 to $12 \mathrm{~h}$, irrespective of forecast category or verification measure.

4) As shown in Fig. 6, for fast responding basins, increases in forecast error jump significantly from 6 and $12 \mathrm{~h}$ QPF durations to longer QPF durations. Specifically, we see (using Table 3 ) that lengthening the duration of QPF from 6 to $24 \mathrm{~h}$, increases ME by $114.9 \%$ (greater than doubling 6 -h ME), MAE by 49.6\% (nearly 1.5 times 6-h MAE), and RMSE by 98.9\% (nearly doubling 6-h RMSE), which is summarized in Table 6. 

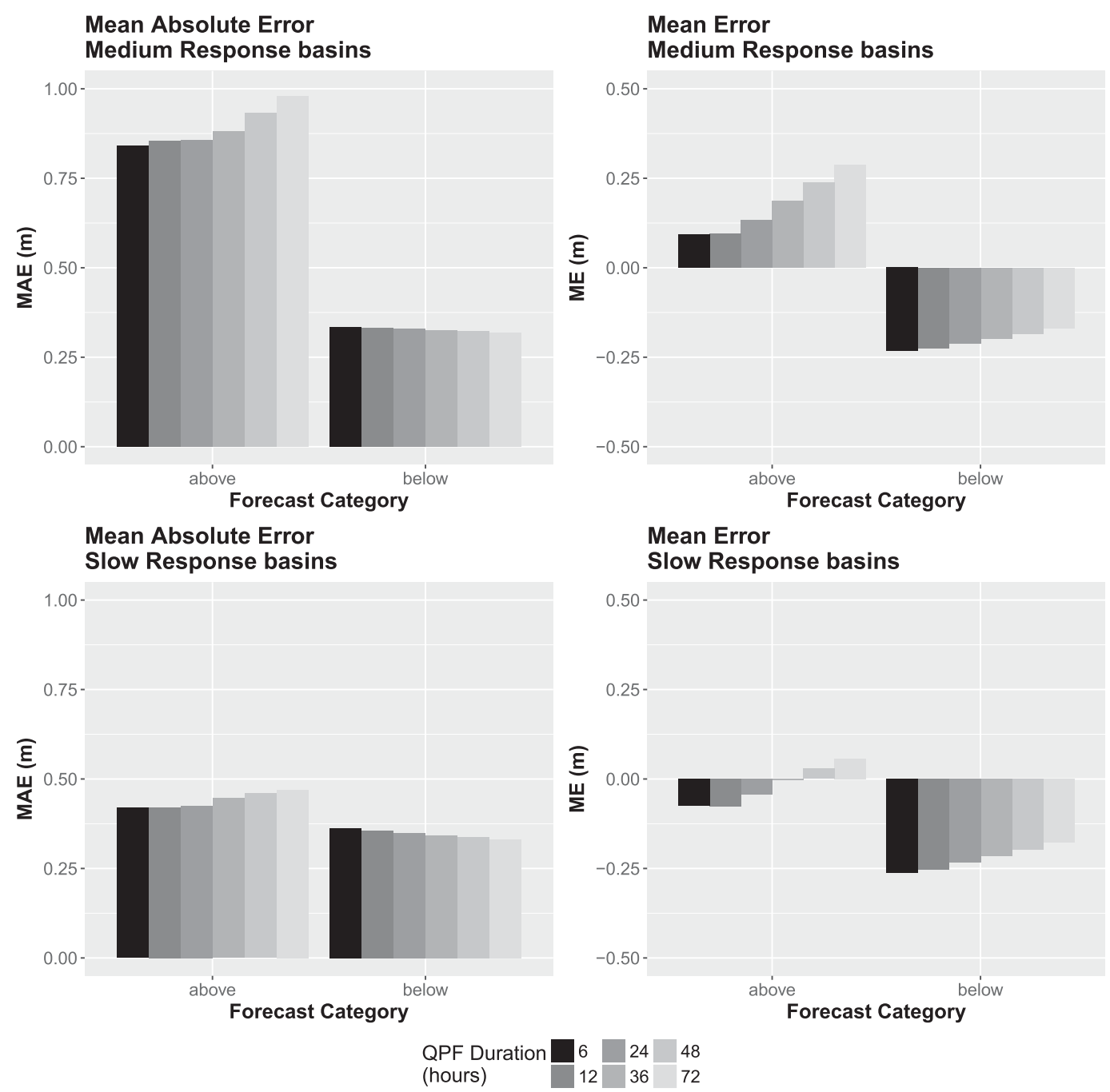

FIG. 5. Experiment 2 (left) MAE and (right) ME for (top) medium and (bottom) slow responding basins, by QPF durations ranging from 6 to $72 \mathrm{~h}$, for above and below flood stage categories. Results are aggregated across all lead times. Shown for the period 23 Jan 2009-15 Sep 2010.

5) Following the cessation of QPF, error statistics begin to converge with lead times $>150 \mathrm{~h}$, as shown in Figs. 2-4. This happens because the influence of the QPF diminishes in time following the last QPF period, subsequent QPF periods are zero, and flows, depending on basin response times, begin to recede with zero QPF forcings.

When forecasts are stratified between flood and nonflood (above/below flood) forecasts, different error structures are evident with respect to lead time. The results in the bottom panels of Fig. 4, for MAE and ME, show that longer durations of QPF lead to reduced hydrologic forecast error for below-flood forecasts. This occurs because, generally, QPF amounts are relatively small for nonflood producing QPF forecasts, which prevents receding hydrographs from decreasing too rapidly relative to watershed response to precipitation accumulations in future periods within the forecast horizon. Longer durations of QPF for below flood forecasts inhibit rapid hydrograph recessions. Figure 5 shows ME (right panels) and MAE (left panels) for medium and slow response basins, respectively, for the six QPF durations, by forecast category. These results show a general trend, for both medium and slow response basins, of increased forecast error for above flood forecasts with longer lead times, but decreasing error for below flood forecasts with increased QPF durations, with longer lead times. Figure 6 shows ME, MAE, and RMSE for QPF durations, grouped by above and below flood forecast categories for fast response basins. Results for ME, MAE, and RMSE verification measures, 

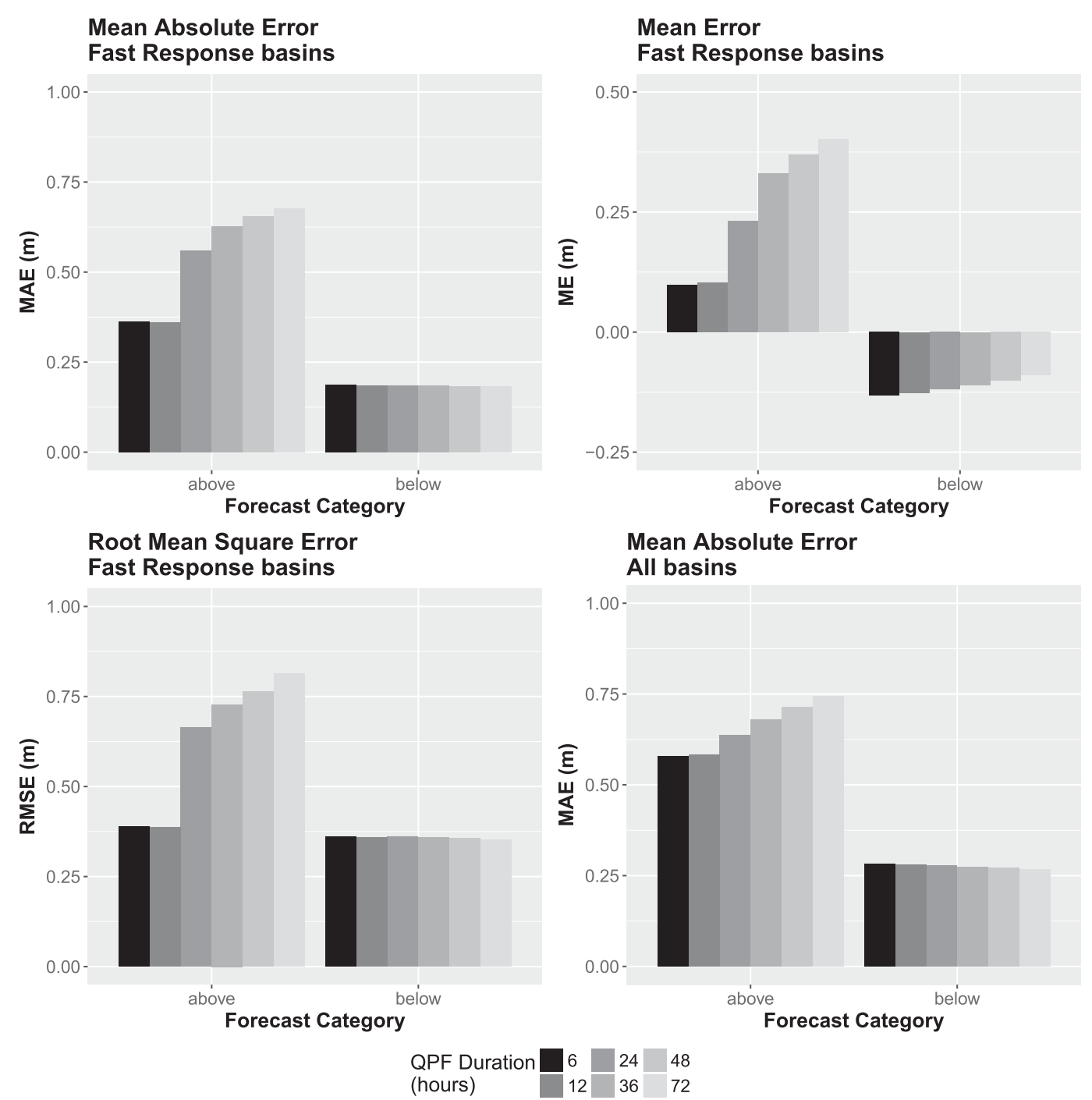

FIG. 6. Experimental results for fast responding Experiment 2 basins, aggregated across all lead times, showing (top left) MAE, (top right) ME, and (bottom left) RMSE for QPF ranging from 6- to 72-h durations. (bottom right) MAE for all basins is included for comparison purposes. Shown for the period 23 Jan 2009-15 Sep 2010.

which are summarized in Figs. 5 and 6 and Table 3, show significant increases in hydrologic forecast error with longer QPF durations for above flood level forecasts. Below flood level forecasts reflect slight decreases in hydrologic forecast error with longer QPF durations. These results demonstrate significant sensitivity of small, fast response basins to QPF error and, one should expect, to errors in observed precipitation forcings, relative to medium and slow response basins.

\section{Discussion}

Forecast verification results from experiments 1 and 2 have demonstrated several key points related to the use of deterministic QPF, namely,
1) the use of nonzero QPF reduces hydrologic forecast error compared to zero QPF;

2) hydrologic forecast error generally increases with longer durations of QPF;

3) with below flood level forecasts, forecast error increases at a slower rate with longer durations of QPF compared to short durations of QPF; and

4) for flood forecasting purposes, the use of QPF beyond $6-12 \mathrm{~h}$ is not recommended due to greatly increased hydrologic forecast error.

The latter point is underscored in Fig. 7, which shows RMSE for all basins and response times, with combined above and below flood category forecasts. Figure 7 shows that hydrologic forecast errors generally increase with longer forecast lead times and 


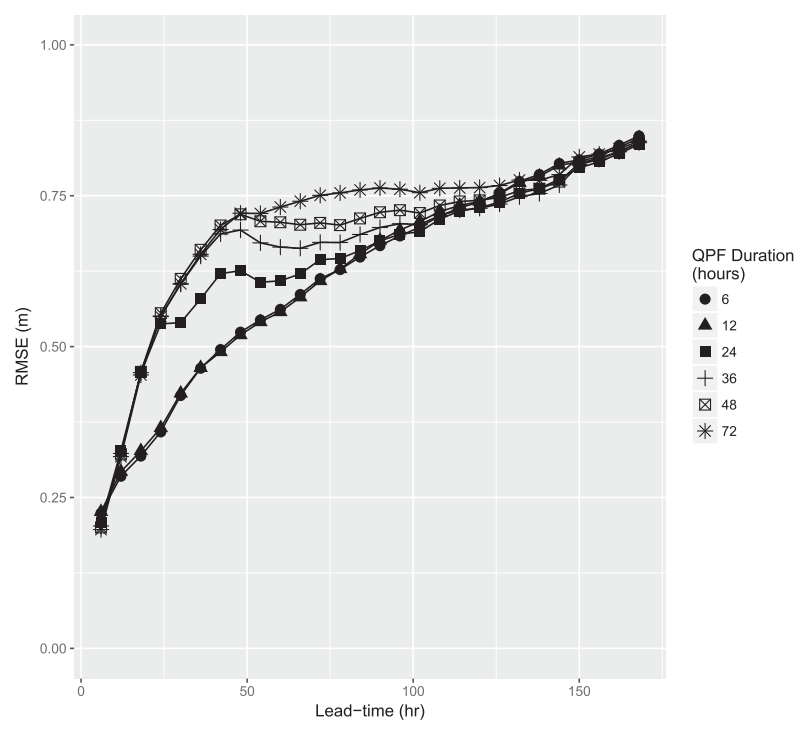

FIG. 7. Experiment 2 RMSE for all basins and response times, by lead time, for the OHRFC QPF forecast scenarios $(6,12,24,36,48$, and $72 \mathrm{~h}$ ). Shown for the period 23 Jan 2009-15 Sep 2010.

with greater durations of QPF and that 6- and 12-h QPF duration RMSE values remain well below RMSE values for all other QPF durations out to lead time $72 \mathrm{~h}$.

We note that experiment 1 forecast verification statistics are consistent with official NWS RFC forecast verification statistics for the period April 2001-October 2016, shown in Table 4, for the OHRFC, and Table 5, for all 13 RFCs. RFC forecast verification statistics can be found at the Performance Management website (NOAA/NWS 2018) for operational forecasts utilizing the full range of RFC QPF, which does vary between RFCs. A further note is that in 2011, the OHRFC changed the use of QPF from 24-h duration (four 6-h periods per day) to 48 -h duration (eight 6-h periods over 2 days) for routine operations.

The findings from experiment 2 show that the use of longer durations of QPF as a model forcing leads to increased hydrologic forecast error, except for below flood forecasts, where errors are reduced with increased durations of QPF. Figure 5 shows smaller MAE values at a given lead time and QPF duration, reflecting smaller error, for slow responding basins relative to medium and fast responding basins, shown in Fig. 6. In turn, smaller MAE values for a given lead time and QPF duration are found with medium response basins than for fast responding basins. This reflects the relative insensitivity of larger watersheds to QPF location errors compared to smaller watersheds. Dramatic increases in flood forecast error for fast responding watersheds were demonstrated for QPF durations $>12 \mathrm{~h}$. Because larger watersheds are composed of many smaller, fast responding basins where flood forecasts are issued, we believe QPF with durations $\leq 12 \mathrm{~h}$ should be recommended for flood forecasting purposes, at least in the broader OHRFC region.

To more fully support this recommendation, 24-h QPF verification results, taken from the NPVU study (Charba et al. 2003), are presented in Fig. 11 for the

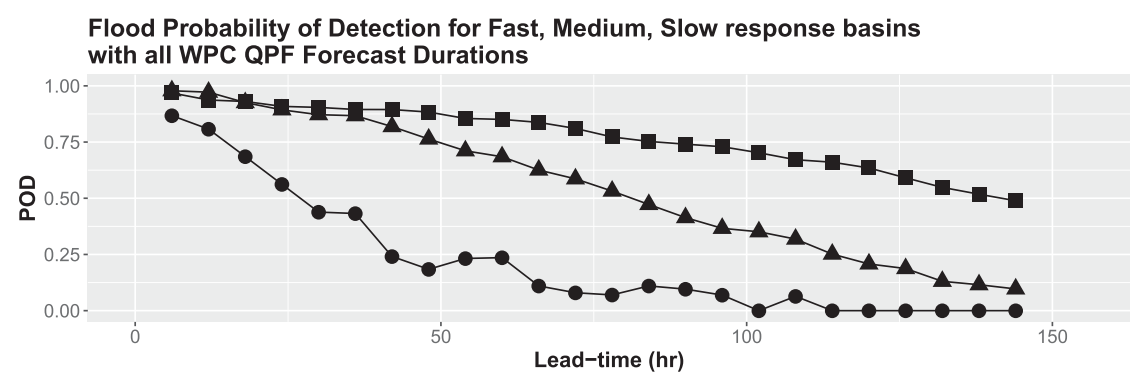

Flood False Alarm Ratio for Fast, Medium, Slow response basins with all WPC QPF Forecast Durations

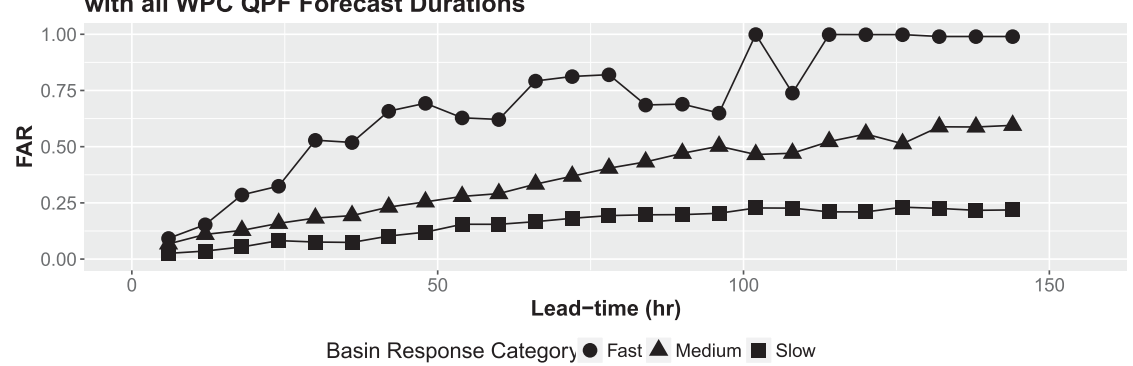

FIG. 8. Experiment 2 (top) POD and (bottom) FAR for flood stage forecasts, by basin response time category and forecast lead time. Shown for the period 23 Jan 2009-15 Sep 2010. 

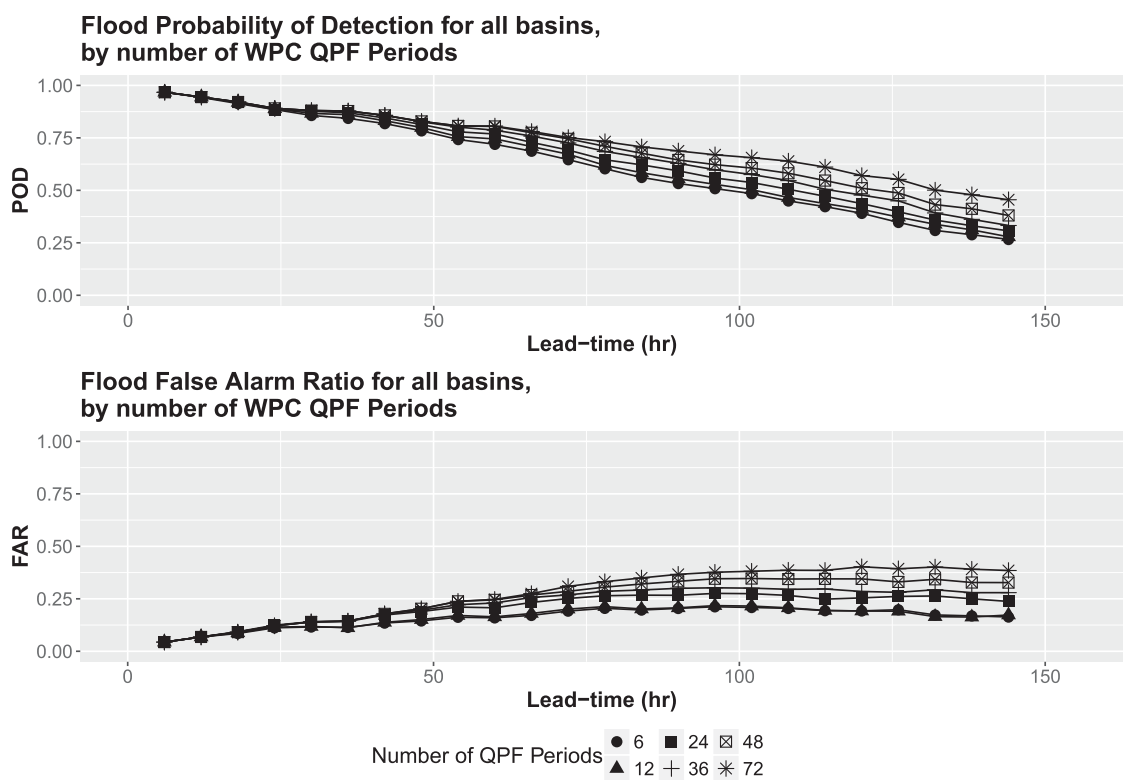

FIG. 9. Experiment 2 (top) POD and (bottom) FAR for flood stage forecasts, for all basins and response times, by number of QPF periods and forecast lead time. Shown for the period 23 Jan 2009-15 Sep 2010.

NOAA/NWS Global Forecast System (GFS) NWP model over CONUS RFC areas. We report GFS verification statistics for two reasons: 1) the underlying data are completely objective and point to fundamental issues related to QPF predictability and 2) GFS QPF is only marginally different from WPC and RFC QPF (Adams and Dymond 2018, manuscript submitted to J. Hydrol.) that is produced with direct forecaster interaction. Consequently, we feel the GFS QPF results are fully representative of QPF findings from WPC and RFCs. MAE values aggregated across all precipitation categories (Fig. 11a) and for the QPF category $\geq$ $25.4 \mathrm{~mm}$ (1.0 in., Fig. 11b) indicate that QPF errors over the OHRFC area are not exceptional compared to most other RFC areas. Figure 11a suggests that greatest QPF predictability exists for areas on the East and West Coasts, with least QPF predictability in the central United States. Consequently, at least from the standpoint of QPF error and predictability, the OHRFC area does not seem too dissimilar compared to most other RFC regions. If anything, these results suggests QPF error and their impacts on hydrologic prediction should be significantly greater over many other RFC forecast regions compared to the OHRFC. MAE for QPF $\geq$ $25.4 \mathrm{~mm}(1.0 \mathrm{in}$.), that is, higher precipitation amounts that are more likely to be associated with floods, shown in Fig. 11b, further supports our contention that the findings for the OHRFC may be widely applicable.

A significant result is shown in Fig. 3, where RMSE for fast response basins is smaller for without WPC QPF than with WPC QPF, for periods 1-3. This demonstrates the sensitivity of smaller, fast response basins to QPF errors, which is much more hit-and-miss than for larger basins. With medium to slow response basins, spatial averaging of model forcings and greater variability of initial conditions can dampen watershed nonlinear response effects (Bevan 2012). This is demonstrated in the lower panels of Fig. 3, where little RMSE difference is seen between with and without WPC QPF for medium and slow response basins for lead times 6-24h.

The sensitivity of small, fast response basins to QPF is also clearly evident with the detection of flood events, shown in Figs. 8 and 10, for FAR, FAR $=b /(a+b)$, and $\mathrm{POD}, \mathrm{POD}=a /(a+c)$, from the contingency table (Table 7). Figure 8 shows a rapid decline of POD for fast response basins relative to medium and slow response basins with increasing lead times and rapidly increasing FAR with increased lead times. With all basins aggregated together, as Fig. 9 shows, the overall sensitivity of flood detection to the number of QPF periods is not apparent, but the trend of decreasing POD and increasing FAR with increased lead times is consistent across the number of QPF periods used in the hydrologic forecasts. However, when hydrologic forecasts are stratified by basin response and the number of QPF periods, as shown in Fig. 10, it is evident that fast response basins show far greater sensitivity to QPF for flood detection than medium and slow response basins. POD declines very rapidly and FAR increases quickly for fast response basins compared to medium and slow 


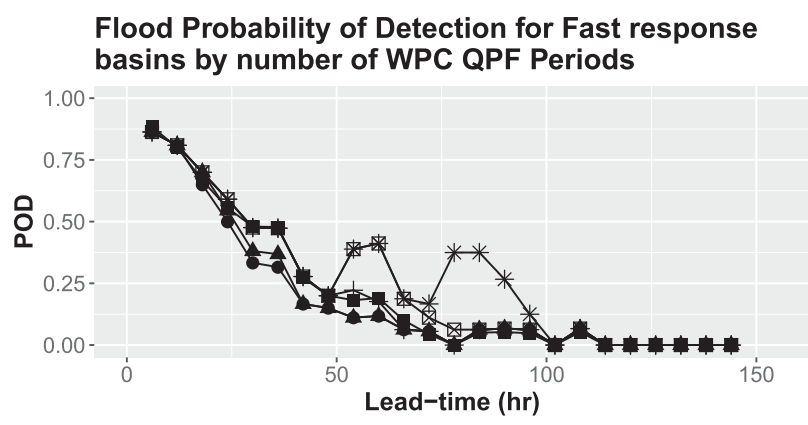

Flood Probability of Detection for Medium response basins by number of WPC QPF Periods

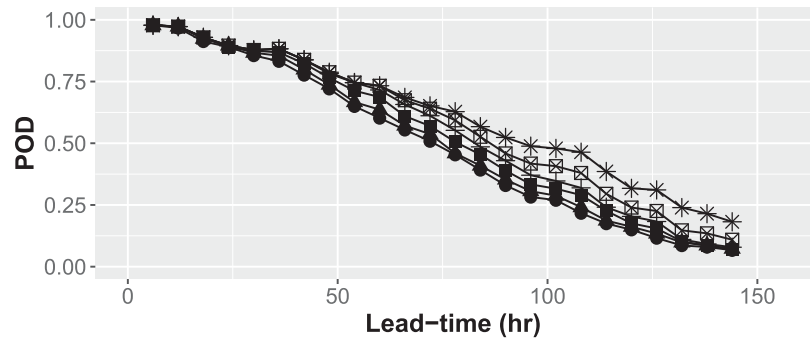

Flood Probability of Detection for Slow response basins by number of WPC QPF Periods

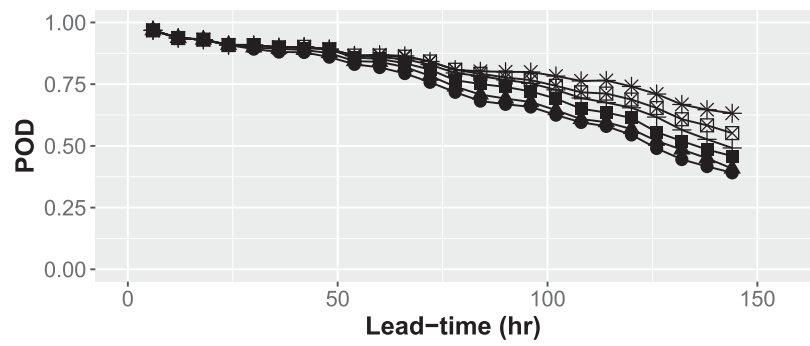

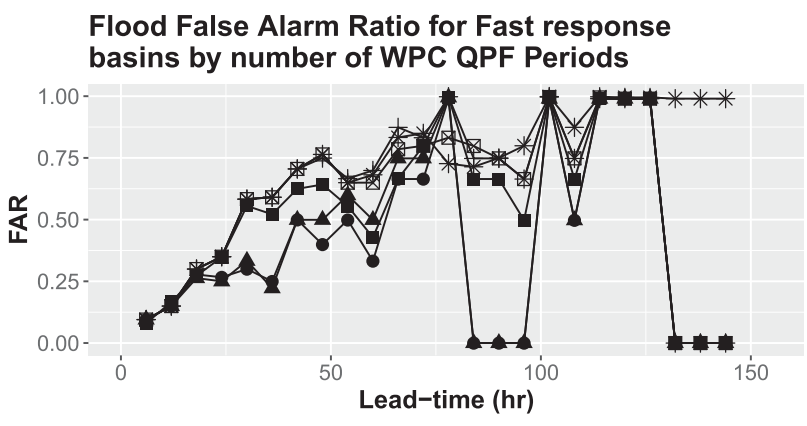

Flood False Alarm Ratio for Medium response basins by number of WPC QPF Periods

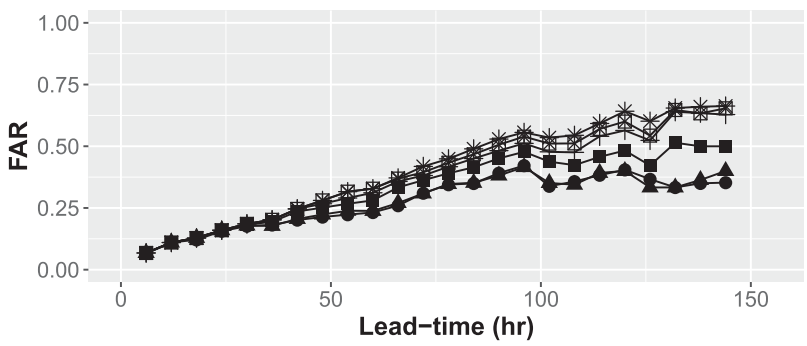

Flood False Alarm Ratio for Slow response basins by number of WPC QPF Periods

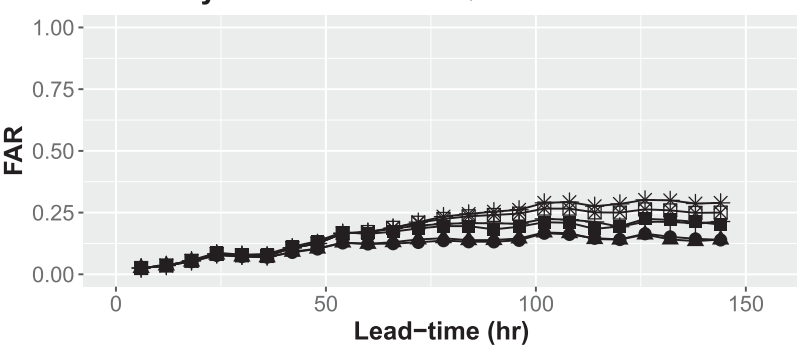

6 - $24 \otimes 48$

A $12+36 * 72$

FIG. 10. Experiment 2 (left) POD and (right) FAR for flood stage forecasts, by number of QPF periods and forecast lead time, shown for each basin response category (fast, medium, and slow). Shown for the period 23 Jan 2009-15 Sep 2010.

response basins, irrespective of the number of QPF periods. Zero-valued FAR points in Fig. 10 (top right), for fast response basins at some longer lead times and some QPF durations, occurred because, with relatively limited sample sizes, there were no flood false alarms (no occurrences of flood forecasts that were not observed).

These results have far-reaching implications in hydrologic forecasting where the use of deterministic QPF is a major component of operational workflows. This is especially evident with the motivation to provide hydrologic forecasts at increasingly finer spatial scales. The NOAA/NWS National Water Model (NWM; http://water.noaa.gov/about/nwm) is representative of this effort, whose aim is to support "street level" flood forecasting, utilizing the 1:100000 scale National Hydrography Dataset-Plus (NHDPlus; Dewald et al. 2019), with the potential to provide hydrologic forecasts at
2.7 million river segments (Salas et al. 2018). We have demonstrated that the errors from hydrologic prediction utilizing deterministic QPF is greatest for smaller basins, especially for the prediction of floods. Lin et al. (2018), using the Weather Research and Forecasting Model hydrological modeling system (WRF-Hydro; Gochis et al. 2015) coupled to the Noah land surface model (LSM) with multiparameterization (Noah-MP; Niu et al. 2011) with atmospheric models and hydrological routing, studied the performance of the NWM at a regional and local scale in the Texas Hill Country for some high-impact flood events. (Lin et al. 2018) describe this modeling system as a physically based model whose configuration resembles the NWM. They found median Nash-Sutcliffe efficiency (NSE) values on the order of $\sim 0.3$ for the 43 basins modeled over the study period utilizing several sources of observed precipitation 
TABLE 3. ME, MAE, and RMSE for experiment 2 forecasts, averaged across all lead times, compared to USGS observed stage values, for 39 NOAA/NWS OHRFC forecast point locations, by QPF duration (hours), for fast, medium, slow, and combined (all) basin response times and above and below flood stage forecast categories. Shown for the period 23 Jan 2009-15 Sep 2010. Units are expressed in meters.

\begin{tabular}{|c|c|c|c|c|c|c|c|c|c|}
\hline \multirow[b]{2}{*}{ QPF Duration } & & \multicolumn{2}{|c|}{ Fast } & \multicolumn{2}{|c|}{ Medium } & \multicolumn{2}{|c|}{ Slow } & \multicolumn{2}{|c|}{ All } \\
\hline & & Above & Below & Above & Below & Above & Below & Above & Below \\
\hline \multirow[t]{3}{*}{6} & $\mathrm{ME}$ & 0.1147 & -0.1398 & 0.0668 & -0.2540 & -0.0874 & -0.31810 & 0.0382 & -0.2222 \\
\hline & MAE & 0.3790 & 0.1950 & 0.8157 & 0.3517 & 0.4195 & 0.4137 & 0.5621 & 0.3035 \\
\hline & RMSE & 0.2994 & 0.3443 & 0.6828 & 0.5760 & 0.5635 & 0.6477 & 0.5577 & 0.5081 \\
\hline \multirow[t]{3}{*}{12} & ME & 0.1013 & -0.1342 & 0.0736 & -0.2466 & -0.0814 & -0.3063 & 0.0382 & -0.2147 \\
\hline & MAE & 0.3754 & 0.1939 & 0.8244 & 0.3489 & 0.4192 & 0.4071 & 0.5643 & 0.3007 \\
\hline & RMSE & 0.2981 & 0.3423 & 0.7067 & 0.5700 & 0.5704 & 0.6388 & 0.5705 & 0.5030 \\
\hline \multirow[t]{3}{*}{24} & ME & 0.2465 & -0.1267 & 0.1113 & -0.2332 & -0.0458 & -0.2843 & 0.1190 & -0.2020 \\
\hline & MAE & 0.5668 & 0.1944 & 0.8244 & 0.3456 & 0.4229 & 0.3988 & 0.6229 & 0.2979 \\
\hline & RMSE & 0.5955 & 0.3424 & 0.7173 & 0.5650 & 0.5793 & 0.6247 & 0.6415 & 0.4981 \\
\hline \multirow[t]{3}{*}{36} & ME & 0.3445 & -0.1173 & 0.1660 & -0.2203 & -0.0030 & -0.2641 & 0.1894 & -0.1892 \\
\hline & MAE & 0.6406 & 0.1927 & 0.8049 & 0.3422 & 0.4438 & 0.3906 & 0.6570 & 0.2943 \\
\hline & RMSE & 0.6520 & 0.3396 & 0.7666 & 0.5578 & 0.6201 & 0.6153 & 0.6917 & 0.4920 \\
\hline \multirow[t]{3}{*}{48} & $\mathrm{ME}$ & 0.3863 & -0.1082 & 0.2146 & -0.2073 & 0.0397 & -0.2441 & 0.2340 & -0.1764 \\
\hline & MAE & 0.6737 & 0.1914 & 0.8495 & 0.3389 & 0.4659 & 0.3831 & 0.6920 & 0.2910 \\
\hline & RMSE & 0.6715 & 0.3371 & 0.8343 & 0.5511 & 0.6398 & 0.6061 & 0.7316 & 0.4863 \\
\hline \multirow[t]{3}{*}{72} & $\mathrm{ME}$ & 0.4212 & -0.0963 & 0.2585 & -0.1907 & 0.0767 & -0.2202 & 0.2730 & -0.1603 \\
\hline & MAE & 0.6985 & 0.1902 & 0.8912 & 0.3350 & 0.4839 & 0.3748 & 0.7218 & 0.2874 \\
\hline & RMSE & 0.7080 & 0.3345 & 0.9002 & 0.5436 & 0.6539 & 0.5964 & 0.7745 & 0.4801 \\
\hline
\end{tabular}

forcings. The authors cite as possible explanations for model performance issues 1) Noah-MP baseflow calculation problems needing future development and calibration; 2) simulated flood hydrographs that are more flashy and have earlier peaks than what is observed, which is reportedly a common problem also seen in the operational NWM; and 3) flood routing parameter estimation issues. If the magnitude of these modeling errors is combined with prediction errors resulting from the use of deterministic QPF, we should be concerned with the ability of these high-resolution modeling systems to provide accurate predictions for small to medium size headwater watersheds. With the benefit of streamflow routing and assimilation of observed flows, downstream predictions are not nearly as problematic, as our results demonstrate.

TABLE 4. Verification statistics for the NOAA/NWS OHRFC, for above and below flood stage, and combined (both above and below) forecasts, showing ME, MAE, and RMSE, expressed in feet, for April 2001-October 2016. Variable $N$ is the number of observationforecast pairs.

\begin{tabular}{|c|c|c|c|c|c|c|c|c|c|c|c|c|}
\hline \multirow[b]{2}{*}{ Time } & \multicolumn{4}{|c|}{ Below flood stage } & \multicolumn{4}{|c|}{ Above flood stage } & \multicolumn{4}{|c|}{ Combined flood stage } \\
\hline & $N$ & RMSE & MAE & $\mathrm{ME}$ & $N$ & RMSE & MAE & $\mathrm{ME}$ & $N$ & RMSE & MAE & $\mathrm{ME}$ \\
\hline 6 & 409970 & 0.330 & 0.199 & 0.013 & 15328 & 0.735 & 0.594 & -0.373 & 425298 & 0.345 & 0.213 & -0.001 \\
\hline 12 & 417986 & 0.465 & 0.294 & 0.013 & 16227 & 1.049 & 0.813 & -0.462 & 434213 & 0.487 & 0.313 & -0.005 \\
\hline 18 & 410393 & 0.587 & 0.368 & 0.022 & 15629 & 1.275 & 1.008 & -0.572 & 426022 & 0.612 & 0.392 & 0.000 \\
\hline 24 & 422208 & 0.685 & 0.437 & 0.027 & 16700 & 1.398 & 1.110 & -0.629 & 438908 & 0.713 & 0.463 & 0.002 \\
\hline 30 & 408590 & 0.758 & 0.484 & 0.022 & 15397 & 1.623 & 1.317 & -0.787 & 423987 & 0.789 & 0.515 & -0.008 \\
\hline 36 & 415890 & 0.814 & 0.530 & 0.013 & 15654 & 1.804 & 1.434 & -0.874 & 431544 & 0.849 & 0.562 & -0.019 \\
\hline 42 & 408475 & 0.887 & 0.575 & 0.009 & 14794 & 1.919 & 1.546 & -0.932 & 423269 & 0.923 & 0.609 & -0.024 \\
\hline 48 & 421407 & 0.953 & 0.624 & -0.009 & 15823 & 1.973 & 1.575 & -0.962 & 437230 & 0.990 & 0.658 & -0.044 \\
\hline 54 & 407480 & 1.003 & 0.655 & -0.045 & 14462 & 2.194 & 1.787 & -1.164 & 421942 & 1.044 & 0.694 & -0.083 \\
\hline 60 & 415397 & 1.042 & 0.689 & -0.087 & 14638 & 2.385 & 1.912 & -1.286 & 430035 & 1.088 & 0.731 & -0.128 \\
\hline 66 & 407558 & 1.105 & 0.727 & -0.128 & 13862 & 2.529 & 2.057 & -1.433 & 421420 & 1.152 & 0.771 & -0.170 \\
\hline 72 & 420469 & 1.166 & 0.773 & -0.181 & 14864 & 2.645 & 2.139 & -1.527 & 435333 & 1.217 & 0.820 & -0.227 \\
\hline All proj & 4965823 & 0.817 & 0.530 & -0.028 & 183378 & 1.775 & 1.42 & -0.903 & 5149201 & 0.851 & 0.562 & -0.059 \\
\hline Day 1 & 1660557 & 0.518 & 0.325 & 0.019 & 63884 & 1.120 & 0.886 & -0.511 & 1724441 & 0.540 & 0.346 & -0.001 \\
\hline Day 2 & 1654362 & 0.854 & 0.554 & 0.008 & 61668 & 1.830 & 1.468 & -0.889 & 1716030 & 0.889 & 0.586 & -0.024 \\
\hline Day 3 & 1650904 & 1.080 & 0.711 & -0.111 & 57826 & 2.439 & 1.974 & -1.352 & 1708730 & 1.126 & 0.754 & -0.153 \\
\hline All days & 4965823 & 0.817 & 0.530 & -0.028 & 183378 & 1.775 & 1.425 & -0.903 & 5149201 & 0.851 & 0.562 & -0.059 \\
\hline
\end{tabular}


TABLE 5. Verification statistics for all NOAA/NWS RFCs, for above and below flood stage, and combined (both above and below) forecasts, showing ME, MAE, and RMSE, expressed in feet, for April 2001-October 2016. Variable $N$ is the number of observationforecast pairs.

\begin{tabular}{|c|c|c|c|c|c|c|c|c|c|c|c|c|}
\hline \multirow[b]{2}{*}{ Time } & \multicolumn{4}{|c|}{ Below flood stage } & \multicolumn{4}{|c|}{ Above flood stage } & \multicolumn{4}{|c|}{ Combined flood stage } \\
\hline & $N$ & RMSE & MAE & ME & $N$ & RMSE & MAE & $\mathrm{ME}$ & $N$ & RMSE & MAE & $\mathrm{ME}$ \\
\hline 6 & 4670053 & 0.261 & 0.159 & 0.016 & 248967 & 0.410 & 0.308 & -0.142 & 4919020 & 0.268 & 0.166 & 0.008 \\
\hline 12 & 4684457 & 0.367 & 0.228 & 0.024 & 256717 & 0.672 & 0.517 & -0.220 & 4941174 & 0.383 & 0.243 & 0.011 \\
\hline 18 & 4694310 & 0.454 & 0.285 & 0.036 & 248630 & 0.855 & 0.662 & -0.301 & 4942940 & 0.475 & 0.304 & 0.019 \\
\hline 24 & 4888601 & 0.515 & 0.326 & 0.042 & 249815 & 0.984 & 0.768 & -0.396 & 5138416 & 0.538 & 0.348 & 0.021 \\
\hline 30 & 4688068 & 0.578 & 0.371 & 0.039 & 241304 & 1.127 & 0.889 & -0.489 & 4929372 & 0.605 & 0.396 & 0.013 \\
\hline 36 & 4687903 & 0.626 & 0.406 & 0.031 & 239426 & 1.270 & 1.012 & -0.558 & 4927329 & 0.658 & 0.436 & 0.002 \\
\hline 42 & 4694345 & 0.672 & 0.439 & 0.026 & 232476 & 1.365 & 1.092 & -0.618 & 4926821 & 0.704 & 0.470 & -0.005 \\
\hline 48 & 4885648 & 0.710 & 0.464 & 0.019 & 233029 & 1.452 & 1.162 & -0.710 & 5118677 & 0.744 & 0.496 & -0.014 \\
\hline 54 & 4562969 & 0.744 & 0.492 & -0.008 & 222518 & 1.560 & 1.254 & -0.800 & 4785487 & 0.782 & 0.528 & -0.045 \\
\hline 60 & 4288623 & 0.782 & 0.521 & -0.025 & 218516 & 1.691 & 1.363 & -0.869 & 4507139 & 0.826 & 0.562 & -0.066 \\
\hline 66 & 4266722 & 0.813 & 0.546 & -0.045 & 212815 & 1.778 & 1.434 & -0.938 & 4479537 & 0.859 & 0.589 & -0.087 \\
\hline 72 & 4359841 & 0.844 & 0.568 & -0.061 & 213384 & 1.882 & 1.522 & -1.027 & 4573225 & 0.892 & 0.613 & -0.106 \\
\hline All proj & 55371540 & 0.610 & 0.397 & 0.009 & 2817597 & 1.228 & 0.978 & -0.572 & 58189137 & 0.640 & 0.425 & -0.019 \\
\hline Day 1 & 18937421 & 0.401 & 0.251 & 0.030 & 1004129 & 0.730 & 0.564 & -0.264 & 19941550 & 0.417 & 0.266 & 0.015 \\
\hline Day 2 & 18955964 & 0.647 & 0.420 & 0.028 & 946235 & 1.302 & 1.037 & -0.592 & 19902199 & 0.678 & 0.450 & -0.001 \\
\hline Day 3 & 17478155 & 0.795 & 0.531 & -0.034 & 867233 & 1.726 & 1.391 & -0.907 & 18345388 & 0.839 & 0.572 & -0.076 \\
\hline All days & 55371540 & 0.610 & 0.397 & 0.009 & 2817597 & 1.228 & 0.978 & -0.572 & 58189137 & 0.640 & 0.425 & -0.019 \\
\hline
\end{tabular}

An unaddressed issue is how QPF uncertainty is translated into an expression of uncertainty in hydrologic forecasting. Advancements in probabilistic and ensemble hydrologic forecasting capture the need to quantify hydrologic forecast uncertainty, particularly as it relates to QPF uncertainty (Cloke and Pappenberger 2009; Adams and Ostrowski 2010; Demargne et al. 2014; Adams and Dymond 2018). We believe that the findings from this study, taken together with conclusions drawn from Adams and Dymond (2018, manuscript submitted to J. Hydrol.), which quantifies the magnitude of hydrologic forecast error that can ensue from the use of deterministic QPF, underscores the necessity for the use of ensemble, or, more generally, probabilistic hydrologic forecasting over deterministic forecasting using single-valued deterministic QPF.

We illustrate the need for hydrologic forecast accuracy with an example. Two OHRFC forecast hydrographs, generated approximately $24 \mathrm{~h}$ apart are shown in Fig. 12, for the Scioto River basin defined at Circleville, OH (USGS ID 03230700; identified in Fig. 1). The forecast issuance times and dates are 1442 UTC 30 March 2019 (Fig. 12a) and 1348 UTC 31 March 2019 (Fig. 12b); the forecast hydrograph for 0154 UTC 2 April 2019, shown in Fig. 12c, captures the observed flood crest. The graphics are taken from NOAA/NWS (2019b). Figure 12 shows

1) the rapid rise in basin response to observed precipitation in Fig. 12a, shown by the blue dots;

2) the hydrograph peak in Fig. 12a is due to a combination of both observed precipitation and QPF;
3) that the forecast in Fig. 12a falls just short of flood stage;

4) the updated forecast the following day (Fig. 12b) is the result of observed rainfall only, as a sharp frontal boundary had passed through the region;

5) the updated forecast (Fig. 12b) shows the flood peak exceeding the minor flood level; and

6) the observed crest (Fig. 12c) occurred at 1630 UTC 1 April 2019 at $17.08 \mathrm{ft}(5.21 \mathrm{~m})$, approximately $12 \mathrm{~h}$ later and $2.5 \mathrm{ft}(0.76 \mathrm{~m})$ higher than the 1442 UTC 30 March 2019 forecast.

Figure 12, showing OHRFC Advanced Hydrologic Prediction Services (AHPS) (McEnery et al. 2005; NRC 2006) hydrographs, is a reasonably typical forecast scenario, illustrating the small margins for error, especially as they relate to local flood impacts (cf. Fig. 12 to Table 8). It should be noted that the AHPS forecast hydrographs are updated hourly to

TABLE 6. Summary of hydrologic forecast error change (\%) from 6-h duration WPC QPF to 12-, 24-, 36-, 48-, and 72-h durations for fast responding basins, for above flood stage category forecasts, from Table 3.

\begin{tabular}{cccc}
\hline \hline QPF duration & ME & MAE & RMSE \\
\hline 6 & - & - & - \\
12 & -11.7 & -0.9 & -0.4 \\
24 & 114.9 & 49.6 & 98.9 \\
36 & 200.3 & 69.0 & 117.8 \\
48 & 236.8 & 77.8 & 124.3 \\
72 & 267.2 & 84.3 & 136.5 \\
\hline
\end{tabular}


(a)

GFS model MAE by NWS RFC 2001-2009, all QPF categories

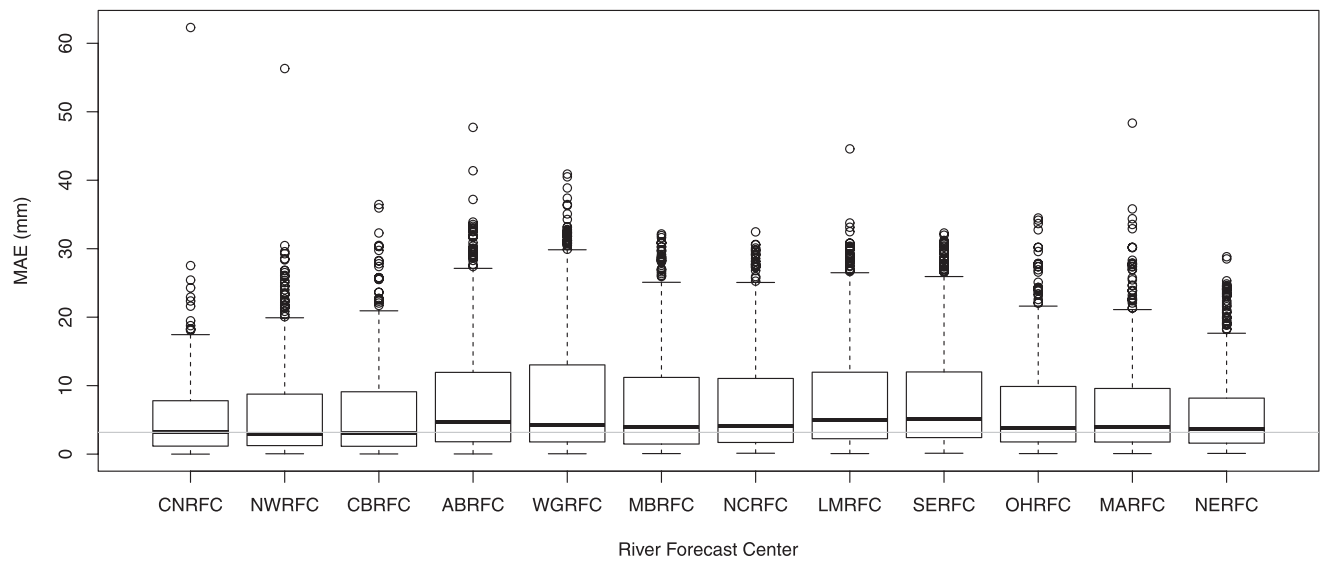

(b) GFS model MAE by NWS RFC 2001-2009, QPF .GE. $25.4 \mathrm{~mm}$

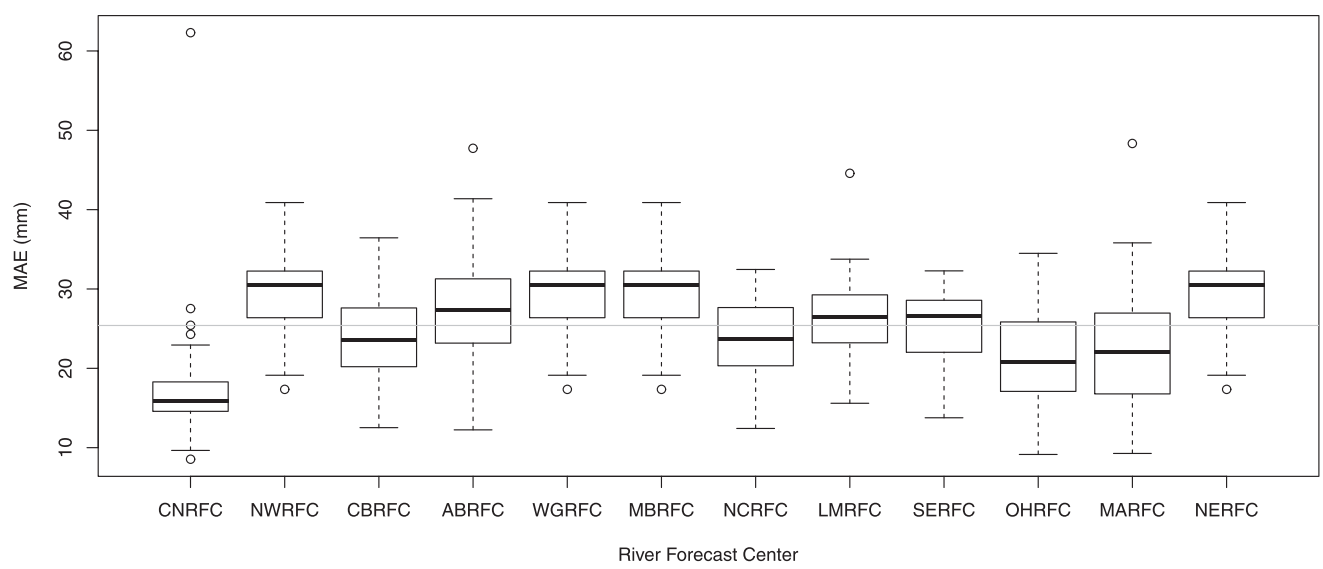

(c)

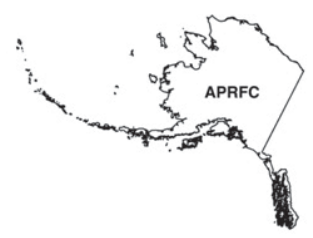

is

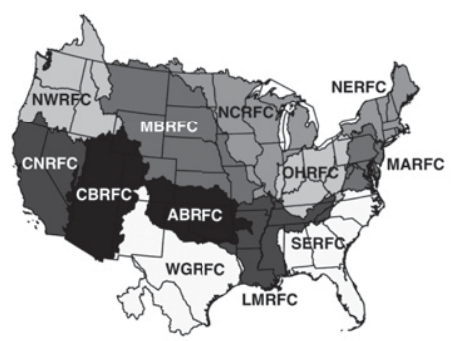

FIG. 11. NOAA/NWS NPVU GFS 24-h QPF verification, 2001-09, for 12 CONUS RFCs and the Alaska-Pacific RFC (APRFC). 
TABLE 7. Contingency table.

\begin{tabular}{ccc}
\hline \hline & \multicolumn{2}{c}{ Observed } \\
\cline { 2 - 3 } Forecast & Yes & No \\
\hline Yes & $a$ & $b$ \\
No & $c$ & $d$ \\
\hline
\end{tabular}

reflect the acquisition of new river stage observations and not necessarily (and usually not) updated hydrologic forecasts. Several important river levels (action, minor, moderate, major, record) are indicated in the AHPS graphics. These are used by NWS forecasters in the alert and warning process to benefit local emergency managers and others for flood preparedness and action. However, significantly greater detail is available on flood impacts when river levels reach or exceed certain stages, as shown in Table 8. This implies that the demands for hydrologic forecast accuracy can be quite specific, which categorical statements on exceeding pre-established flood levels cannot fully capture.

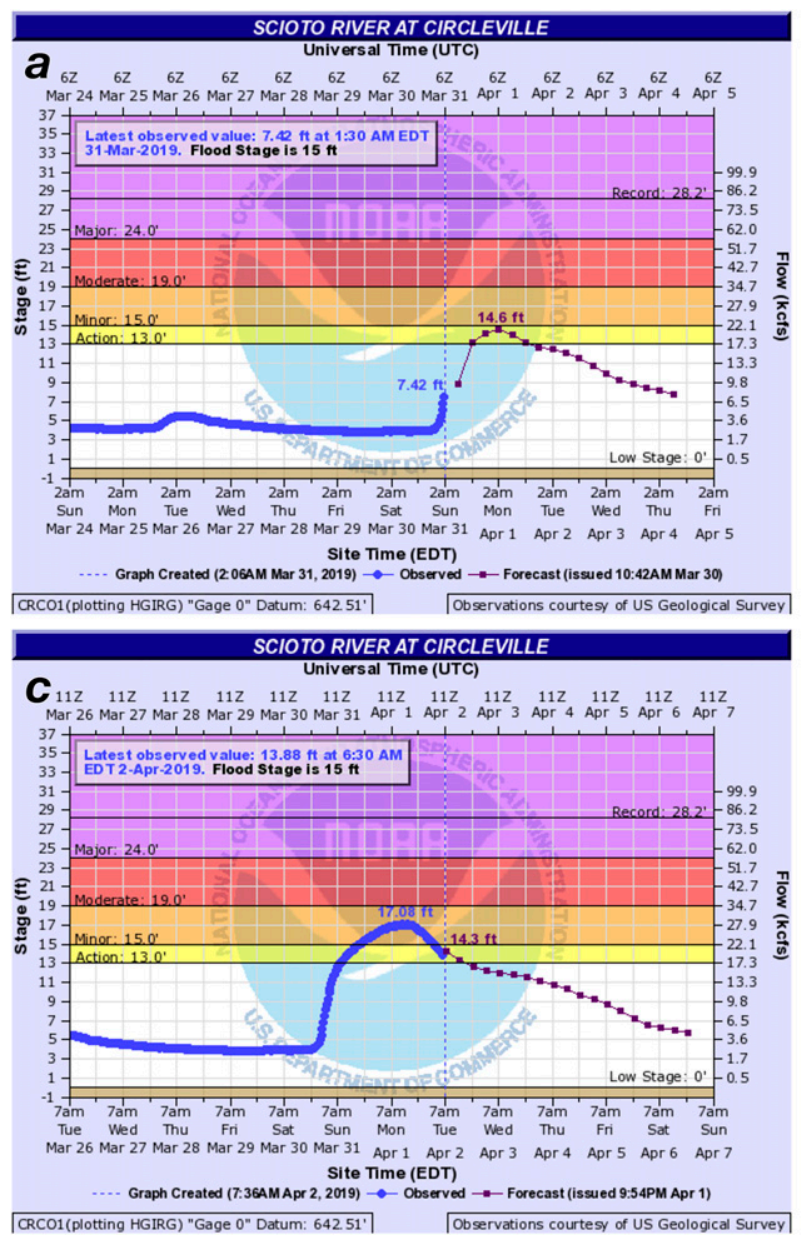

\section{Summary and conclusions}

Overall, the results presented demonstrate the need to stratify verification analyses into basin size/response times, number of periods of QPF used, etc. to fully assess the impact of using deterministic QPF for operational hydrologic forecasting. We also identify a direct conflict between the use of deterministic QPF for flood forecasting versus meeting broader needs for other water resources applications that require longer lead times. With the former, only one or two periods of QPF seems warranted, but for the latter, QPF should be use for the entire forecast horizon.

Two independent sets of real-time experimental forecasts, initialized with 1200 UTC saved model states from OHRFC daily operational forecasts, were conducted to assess the value of deterministic QPF as a model forcing in hydrologic forecasting. Specifically, in experiment 1 , we investigated if the use of nonzero QPF as a model forcing produced hydrologic forecasts exhibiting smaller forecast error than hydrologic forecasts using zero-valued QPF. Experiment 2 examined

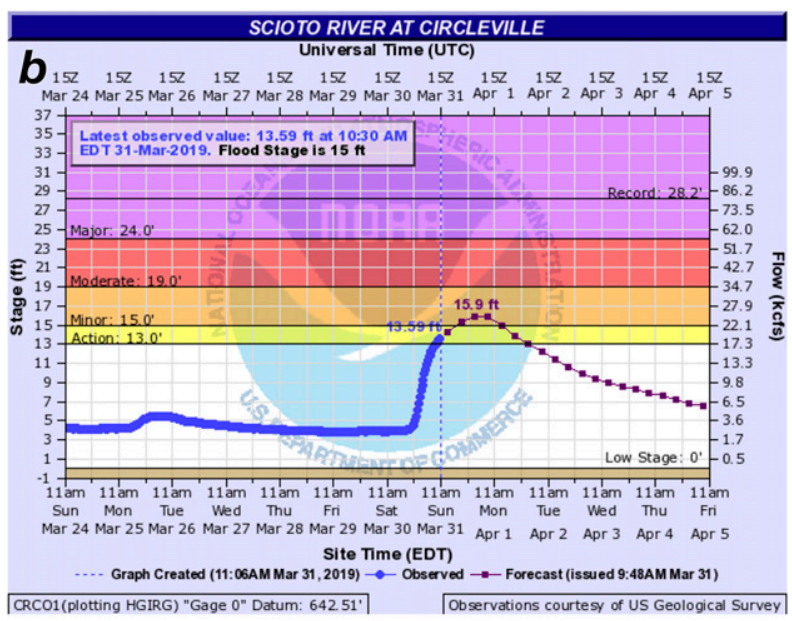

FIG. 12. OHRFC AHPS forecast hydrographs (a) 1442 UTC 30 Mar 2019, (b) 1348 UTC 31 Mar 2019, and (c) 0154 UTC 2 Apr 2019 for the Scioto River basin defined at Circleville, OH (USGS ID 03230700). Stage values are in feet relative to a local datum, and flows are in thousands of cubic feet per second ( $\mathrm{kcfs}$ ). 
TABLE 8. NOAA/NWS flood impacts for Circleville, OH (CRCO1), USGS ID 03230700. Flood stage is $15.0 \mathrm{ft}$ (4.57 m).

\begin{tabular}{|c|c|}
\hline Stage $(\mathrm{ft})$ & Impact \\
\hline 28.2 & $\begin{array}{l}\text { This is the flood of record, which occurred in March 1913. The City of Circleville is elevated above even this record stage } \\
\text { with structures within the city not affected until } 30 \mathrm{ft} \text {. Significant flooding occurs in surrounding areas, especially to the } \\
\text { west and north of Circleville. Major flooding occurs along Mill and Canal Roads, as well as Island Road and State } \\
\text { Route } 762 \text {. Backwater flooding affects areas along Big Darby Creek, especially near the Old Shady Acres Mobile } \\
\text { Home Park. }\end{array}$ \\
\hline 26.5 & $\begin{array}{l}\text { This is similar to the FEMA } 1 \% \text { flood. Major flooding occurs to the west and north of Circleville, including Mill, Canal, } \\
\text { and Island Roads. However, Circleville itself is not impacted until about } 30 \mathrm{ft} \text {. Parts of State Route } 762 \text { and State } \\
\text { Route } 316 \text { are flooded and some sections of Route } 23 \text { may also be impacted. In addition, backwater flooding affects } \\
\text { areas along Big Darby Creek, especially near the Old Shady Acres Mobile Home Park. }\end{array}$ \\
\hline 25.0 & $\begin{array}{l}\text { Significant flooding occurs in surrounding areas, with structures and property flooded along areas of Canal and Island } \\
\text { Roads west and north of Circleville, as well as State Route 762. Backwater flooding affects areas along Big Darby } \\
\text { Creek, especially near the Old Shady Acres Mobile Home Park. Circleville itself is not impacted until about } 30 \mathrm{ft} \text {. }\end{array}$ \\
\hline 23.0 & $\begin{array}{l}\text { Significant flooding occurs in surrounding areas, especially to the west and north of Circleville. Moderate flooding occurs } \\
\text { along Mill and Canal Roads, as well as Island Road and State Route 762. Backwater flooding affects areas along Big } \\
\text { Darby Creek, especially near the Old Shady Acres Mobile Home Park. High water overtakes much of Cooks Creek } \\
\text { Golf Course. Circleville itself would not flood until a stage of } 30 \mathrm{ft} \text {. }\end{array}$ \\
\hline 21.0 & $\begin{array}{l}\text { Serious flooding occurs west of Circleville along Mill and Canal Roads, as well as Island Road and State Route } 762 \text {. } \\
\text { Backwater flooding can be expected near Big Darby Creek, while Cooks Creek Golf Course is flooded. }\end{array}$ \\
\hline 20.0 & $\begin{array}{l}\text { Serious flooding occurs mainly west of Circleville along Mill and Canal Roads, as well as Island Road and State Route } \\
\text { 762. Backwater flooding along Big Darby Creek causes flooding near the Old Shady Acres Mobile Home Park. The } \\
\text { City of Circleville itself is not affected until a stage near } 30 \mathrm{ft} \text {. }\end{array}$ \\
\hline 19.0 & $\begin{array}{l}\text { Flooding may affect businesses near Mill and Canal Roads, as well as Island road and State Route 762. Backwater } \\
\text { flooding along Big Darby Creek causes flooding near the Old Shady Acres Mobile Home Park. The city of Circleville } \\
\text { itself is not affected until a stage near } 30 \mathrm{ft} \text {. }\end{array}$ \\
\hline 18.5 & $\begin{array}{l}\text { Flooding begins near the Old Shady Acres Mobile Home Park near Big Darby Creek. Flooding also affects low-lying } \\
\text { areas near Little Walnut and Canal and Island Roads. }\end{array}$ \\
\hline 18.0 & $\begin{array}{l}\text { Low-lying areas north of Circleville near Little Walnut begin to flood. Flooding also worsens at the intersection of Canal } \\
\text { Road and State Route } 104 \text { and on Island Road north of Circleville. Backwater flooding occurs along Big Darby Creek } \\
\text { near Circleville. }\end{array}$ \\
\hline 17.5 & $\begin{array}{l}\text { Backwater flooding begins along Big Darby Creek near Circleville. Lowland flooding also occurs along Island Road } \\
\text { north of Circleville and Canal Road near Highway } 104 .\end{array}$ \\
\hline 17.0 & $\begin{array}{l}\text { Lowland flooding continues along the river, with flooding along Island Road worsening. Canal Road near State Route } \\
104 \text { also has flooding, as well as Cooks Creek Golf Course and State Route } 762 \text { in northern Pickaway County. }\end{array}$ \\
\hline 16.0 & Lowland flooding continues along the river and about one foot of water can be expected along portions of Island Road. \\
\hline 15.0 & Low-lying agricultural and bottom land becomes flooded, while flooding begins along Island and Canal Roads. \\
\hline
\end{tabular}

the influence of QPF duration on hydrologic forecast error, if the use of nonzero QPF produces hydrologic forecasts with smaller error than zero-valued QPF forecasts. Both experiment 1 and experiment 2 demonstrate that hydrologic forecast error increases with longer forecast lead times. Experiment 1 forecast verification statistics suggest that the use of nonzero QPF as a hydrologic model forcing produces forecasts with less error than forecasts using zero-valued QPF. Experiment 2 forecast verification statistics indicate that, for above flood forecasts, longer durations of QPF increases hydrologic forecast error irrespective of basin size and hydrologic response time. For nonflood forecasts, longer durations of QPF reduces hydrologic forecast uncertainty. We emphasize the finding from experiment 2 that shows for fast responding basins, for above flood forecasts, the use of QPF beyond 6- or 12-h durations increases hydrologic forecast error dramatically. Consequently, from the perspective of flood forecasting, the use of deterministic QPF should be restricted to 6-12-h durations; beyond this hydrologic forecast errors increase significantly for longer QPF durations, showing marginal benefit for medium response basins and little to no benefit for fast response basins. This finding is reflected by both POD and FAR statistics and is significant for operational flood forecasting because 1) QPF must be consistent across spatial and temporal scales for all subbasins (large and small) and 2) for many hydrometeorological forecasting centers there is pressure for extended deterministic hydrologic forecast lead times, including the use of longer durations of QPF. The results presented in this study show that for flood forecasting purposes, the use of QPF beyond 6-12-h duration will significantly increase hydrologic forecast error. While the authors believe these findings to be universal in scope, we cannot support that conclusion definitively, since the experiments and analyses have been restricted to the OHRFC region. 
We issue caution to those involved in efforts to develop detailed, high-resolution hydrologic forecasting systems utilizing deterministic QPF. Beyond model accuracy concerns that are independent of the forcings, we contend that the findings in this paper show for detailed, high-resolution hydrologic forecast systems, such as the NWM, the use of deterministic QPF will not translate into beneficial and reliable forecasts for small to medium size headwater basins as desired. Consequently, we recommend that all hydrologic forecasts should quantify forecast uncertainty, especially as it relates to QPF uncertainty using ensemble, or more generally, probabilistic approaches.

Acknowledgments. The authors are grateful to Thomas Rench and Ray Davis at the NOAA/NWS Ohio River Forecast Center for providing some of the data used in this study. We also thank the anonymous reviewers for their comments, which helped to improve the manuscript. The raw data used in this study and accompanying guide for accessing the data can be found at https://doi.org/10.5281/zenodo.3247953.

\section{REFERENCES}

Adams, T. E., III, 2016: Flood forecasting in the United States NOAA/National Weather Service. Flood Forecasting: $A$ Global Perspective, T. E. Adams III and T. C. Pagano, Eds., 1st ed., Academic Press., 249-310, https://doi.org/10.1016/ B978-0-12-801884-2.00010-4.

_ river forecasting using state, parameter, and data modifications. Proc. of the Int. Symp. on Engineering Hydrology, San Francisco, CA, EWRI, https://cedb.asce.org/CEDBsearch/ record.jsp? dockey $=0083463$.

— forecasts from numerical weather prediction model ensembles. Proc. World Environmental and Water Resources Congress 2010, Providence, RI, EWRI, https://doi.org/10.1061/41114(371)237.

—_, and T. C. Pagano, Eds., 2016: Flood Forecasting: A Global Perspective. 1st ed. Academic Press, 478 pp.

- , and R. Dymond, 2018: Evaluation and benchmarking of operational short-range ensemble mean and median streamflow forecasts for the Ohio River basin. J. Hydrometeor., 19, 1689-1706, https://doi.org/10.1175/JHM-D-18-0102.1.

Anderson, E. A., 1973: National Weather Service River Forecast System-Snow accumulation and ablation model. NOAA Tech. Memo. NWS HYDRO-17, 87 pp., https://www.wcc.nrcs.usda.gov/ ftpref/wntsc/H\&H/snow/AndersonHYDRO17.pdf.

— 2002: Calibration of conceptual hydrologic models for use in river forecasting. NWS Doc., 372 pp., http://www.nws.noaa.gov/ $\mathrm{oh} / \mathrm{hrl} /$ modelcalibration $/ 1 . \% 20$ Calibration \%20Process/ 1_Anderson_CalbManual.pdf.

Bevan, K., 2012: Rainfall-Runoff Modelling: The Primer. 2nd ed., John Wiley \& Sons, 457 pp., https://doi.org/10.1002/9781119951001.

Burnash, R., 1995: The NWS River Forecast System - Catchment Modeling. Computer Models of Watershed Hydrology, 1 st ed. V. P. Singh, Ed., Water Resources Publications, 311-366.
_ R. Ferral, and R. McGuire, 1973: A generalized streamflow simulation system: Conceptual models for digital computers. Joint Federal and State River Forecast Center, U.S. National Weather Service, and California Department of Water Resources Tech. Rep., 204 pp.

Charba, J. P., D. W. Reynolds, B. E. McDonald, and G. M. Carter, 2003: Comparative verification of recent quantitative precipitation forecasts in the National Weather Service: A simple approach for scoring forecast accuracy. Wea. Forecasting, $\mathbf{1 8}$ 161-183, https://doi.org/10.1175/1520-0434(2003)018<0161: CVORQP $>2.0 . \mathrm{CO} ; 2$.

Cloke, H., and F. Pappenberger, 2009: Ensemble flood forecasting: A review. J. Hydrol., 375, 613-626, https://doi.org/10.1016/ j.jhydrol.2009.06.005.

Cuo, L., T. C. Pagano, and Q. J. Wang, 2011: A review of quantitative precipitation forecasts and their use in short- to medium-range streamflow forecasting. J. Hydrometeor., 12, 713-728, https:// doi.org/10.1175/2011JHM1347.1.

Deltares, 2018: Flood Early Warning System (FEWS). https:// www.deltares.nl/en/software/flood-forecasting-system-delftfews-2/.

Demargne, J., M. Mulluski, K. Werner, T. Adams, S. Lindsey, N. Schwein, W. Marosi, and E. Welles, 2009: Application of forecast verification science to operational river forecasting in the U.S. National Weather Service. Bull. Amer. Meteor. Soc., 90, 779-784, https://doi.org/10.1175/2008BAMS2619.1.

— Hydrologic Ensemble Forecast Service. Bull. Amer. Meteor. Soc., 95, 79-98, https://doi.org/10.1175/BAMS-D-12-00081.1.

Dewald, T., L. McKay, L. Bondelid, J. Johnston, R. Moore, and A. Rea, 2019: NHDPlus Version 2: User Guide. U.S. EPA, 182 pp., https://s3.amazonaws.com/nhdplus/NHDPlusV21/ Documentation/NHDPlusV2_User_Guide.pdf.

Diomede, T., C. Marsigli, A. Montani, F. Nerozzi, and T. Paccagnella, 2014: Calibration of limited-area ensemble precipitation forecasts for hydrological predictions. Mon. Wea. Rev., 142, 2176-2197, https://doi.org/10.1175/MWR-D13-00071.1.

Georgakakos, K. P., and M. D. Hudlow, 1984: Quantitative precipitation forecast techniques for use in hydrologic forecasting. Bull. Amer. Meteor. Soc., 65, 1186-1200, https://doi.org/10.1175/ 1520-0477(1984)065<1186:QPFTFU > 2.0.CO;2.

Gochis, D. J., W. Yu, and D. N. Yates, 2015: The WRF-Hydro model technical description and user's guide, version 3.0. NCAR Tech. Doc., 120 pp., http://www.ral.ucar.edu/projects/ wrf_hydro/.

Kitzmiller, D., D. Miller, R. Fulton, and F. Ding, 2013: Radar and multisensor precipitation estimation techniques in national weather service hydrologic operations. J. Hydrol. Eng., 18, 133 142, https://doi.org/10.1061/(ASCE)HE.1943-5584.0000523.

Lack, S. A., G. L. Limpert, and N. I. Fox, 2010: An object-oriented multiscale verification scheme. Wea. Forecasting, 25, 79-92, https://doi.org/10.1175/2009WAF2222245.1.

Li, J., Y. Chen, H. Wang, J. Qin, J. Li, and S. Chiao, 2017: Extending flood forecasting lead time in a large watershed by coupling WRF QPF with a distributed hydrological model. Hydrol. Earth Syst. Sci., 21, 1279-1294, https://doi.org/10.5194/ hess-21-1279-2017.

Lin, P., L. J. Hopper, Z.-L. Yang, M. Lenz, and J. W. Zeitler, 2018: Insights into hydrometeorological factors constraining flood prediction skill during the May and October 2015 Texas hill country flood events. J. Hydrometeor., 19, 1339-1361, https:// doi.org/10.1175/JHM-D-18-0038.1. 
McEnery, J., J. Ingram, Q. Duan, T. Adams, and L. Anderson, 2005: NOAA's Advanced Hydrologic Prediction Service. Bull. Amer. Meteor. Soc., 86, 375-386, https://doi.org/10.1175/ BAMS-86-3-375.

National Research Council, 2006: Completing the Forecast: Characterizing and Communicating Uncertainty for Better Decisions Using Weather and Climate Forecasts. National Academies Press, 124 pp., https://doi.org/10.17226/11699.

Niu, G.-Y., and Coauthors, 2011: The community Noah land surface model with multiparameterization options (Noah-MP): 1 . Model description and evaluation with local-scale measurements. J. Geophys. Res., 116, D12109, https://doi.org/10.1029/ 2010JD015139.

NOAA/NWS, 1972: National Weather Service River Forecast System forecast procedures. NOAA Tech. Memo. NWS HYDRO-14, 264 pp.

, 2001: National Weather Service Verification Software users' manual. Tech. Doc., 26 pp., https://www.nws.noaa.gov/oh/hrl/ verification/ob3/VerifyUsersManual_ob3.pdf.

__ 2018: Performance management web portal. https:// verification.nws.noaa.gov/services/public/index.aspx.

—_, 2019a: NOAA/NWS WPC QPF verification. https:// www.wpc.ncep.noaa.gov/html/hpcverif.shtml.

_ 2019b: NOAA/NWS AHPS forecasts. https:/water.weather.gov/ ahps/forecasts.php.

Novak, D. R., C. Bailey, K. F. Brill, P. Burke, W. A. Hogsett, R. Rausch, and M. Schichtel, 2014: Precipitation and temperature forecast performance at the weather prediction center. Wea. Forecasting, 29, 489-504, https://doi.org/10.1175/WAF-D-13-00066.1.
NRC, 1997: An Assessment of the Advanced Weather Interactive Processing System: Operational Test and Evaluation of the First System Build. National Academies Press, 52 pp., https:// doi.org/10.17226/5995.

, 2006: Toward a New Advanced Hydrologic Prediction Service (AHPS). National Academies Press, 84 pp., https://doi.org/ 10.17226/11598.

Rempel, M., F. Senf, and H. Deneke, 2017: Object-based metrics for forecast verification of convective development with geostationary satellite data. Mon. Wea. Rev., 145, 3161-3178, https://doi.org/10.1175/MWR-D-16-0480.1.

Salas, F. R., and Coauthors, 2018: Towards real-time continental scale streamflow simulation in continuous and discrete space. J. Amer. Water Resour. Assoc., 54, 7-27, https://doi.org/ 10.1111/1752-1688.12586.

Smith, M. B., D. P. Laurine, V. I. Koren, S. M. Reed, and Z. Zhang, 2013: Hydrologic model calibration in the National Weather Service. Calibration of Watershed Models, Q. Duan et al., Eds., Water Science and Application Series, Vol. 6, Amer. Geophys. Union, 133-152.

Sokol, Z., 2003: MOS-based precipitation forecasts for river basins. Wea. Forecasting, 18, 769-781, https://doi.org/10.1175/15200434(2003)018<0769:MPFFRB > 2.0.CO;2.

Welles, E., 2005: Verification of river stage forecasts. Ph.D. dissertation, University of Arizona, $155 \mathrm{pp}$.

—_- S. Sorooshian, G. Carter, and B. Olsen, 2007: Hydrologic verification: A call for action and collaboration. Bull. Amer. Meteor. Soc., 88, 503-511, https://doi.org/10.1175/ BAMS-88-4-503. 